\title{
The Physiological Assessment and Analysis of the Physical Demand of Riding a Snowmobile
}

\author{
by \\ Tania Pereira \\ A Thesis \\ presented to \\ The University of Guelph
}

In partial fulfilment of requirements

for the degree of

Master of Science

in

Human Health and Nutritional Sciences

Guelph, Ontario, Canada

(C) Tania J. Pereira, December 2018 


\begin{abstract}
THE PHYSIOLOGICAL ASSESSMENT AND ANALYSIS OF THE PHYSICAL DEMAND OF RIDING A SNOWMOBILE
\end{abstract}

Tania J. Pereira

University of Guelph, 2018

\author{
Advisor(s): \\ Dr. Jamie Burr \\ Dr. John Durocher
}

Insufficient physical activity (PA) is associated with numerous chronic diseases and premature mortality, and this challenge of meeting recommended PA guidelines is exacerbated in the winter. Snowmobiling could potentially contribute to PA accumulation, but the objective metabolic and physical demands are unclear. Habitual snowmobile riders responded to a survey describing a typical ride $(\mathrm{n}=4,015)$. Using this data, terrain specific (Mountain or Flatland) testing courses were created and recreational snowmobile riders $(n=40)$ participated in a scaled representative ride $(21 \pm 8 \mathrm{mins})$. The mean riding $\mathrm{VO}_{2}$ was $18.5 \pm 8.4 \mathrm{ml} \cdot \mathrm{kg}^{-1} \cdot \mathrm{min}^{-1}$ (Flatland $13.4 \pm 5.2 \mathrm{ml} \cdot \mathrm{kg}^{-1} \cdot \mathrm{min}^{-1}$, Mountain $\left.25.7 \pm 6.6 \mathrm{ml} \cdot \mathrm{kg}^{-1} \cdot \mathrm{min}^{-1}, \mathrm{p}<0.001\right)$. Muscular fatigue was apparent in maximal handgrip across both riding terrains, suggesting an upper body strength component. Snowmobiling is an activity that generally falls within the moderate intensity activity range and involves both aerobic fitness and muscular strength. The aerobic demand of mountain riding may confer additional benefits as the demand was significantly greater. 


\section{ACKNOWLEDGEMENTS}

Firstly, I would like to thank Dr. Jamie Burr for entrusting me with the opportunity to complete the current project and for his continuous efforts in mentoring my academic career. He has pushed me to be more curious, to become more flexible and to adapt when failure occurs, which is often in research. The last two years have been challenging and exciting, thank you for staying with me and supporting me through all of the trials and tribulations of grad life. I cannot express enough appreciation of the countless hours both during and outside of regular office hours to ensure that I was progressing towards the completion of my degree. You have made me a better writer and a better academic, which I will be eternally grateful for.

I would also like to thank the entire Burr lab for their continued support in data collection, and the writing process. Special thank you to Joshua, Brett, Heather, Trevor, and Chris for your assistance in data collection and your company on the amazing places that this project has taken me. Your continued efforts to convert me to a coffee drinker, although unsuccessful, are appreciated and will not be forgotten. I can always count on the members of our lab to act as a sounding board, clarification check, or personal therapist. A big thank you to Dr. Trevor King and his invaluable mentorship along the latter half of my thesis.

Finally, I would like to acknowledge my parents for providing me with all the opportunities that led me here and their continued support. Special acknowledgement to my significant other, Tyler, who acted as my personal motivator, and dog walker. Even though my travelling often left him home alone with our hyperactive puppy, he has continuously supported and encouraged me. 


\section{TABLE OF CONTENTS}

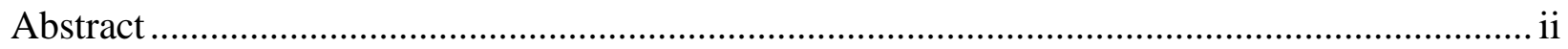

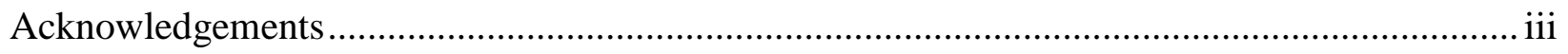

Table of Contents ............................................................................................................ iv

List of Tables ...................................................................................................................... vii

List of Figures .......................................................................................................... vii

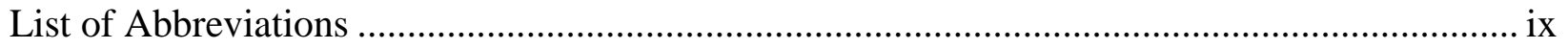

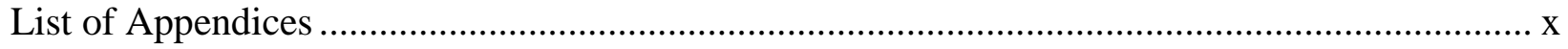

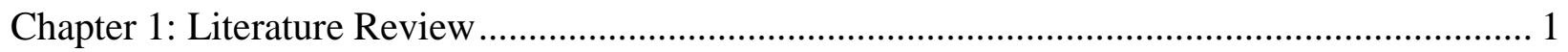

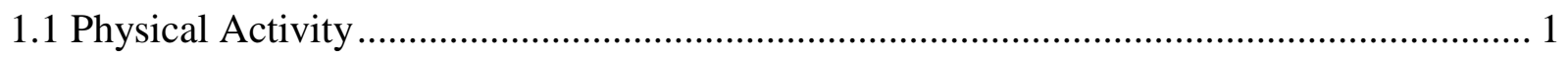

1.1.1 Sedentary Behaviors \& Consequences ......................................................... 1

1.2 Snowmobiling as a Physical Activity Alternative .................................................... 3

1.2.1 Riding-based Activity Comparison.............................................................. 6

1.2.2 Altered Cardiovascular Response to Exercise ................................................... 8

1.2.3 Potential Mental Health Benefits of Participation .............................................. 10

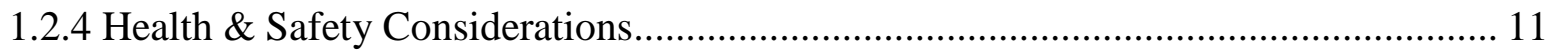

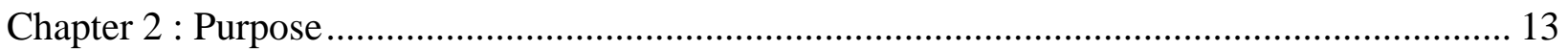

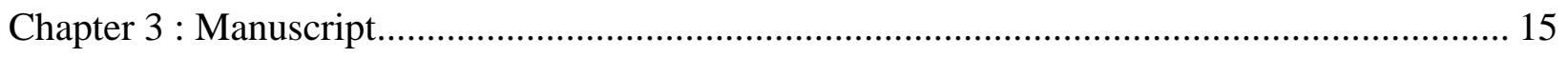

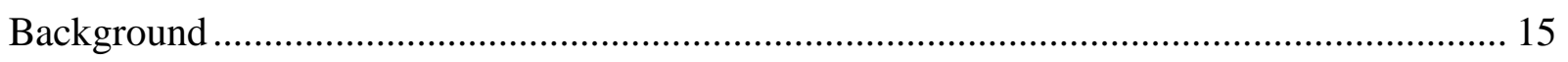

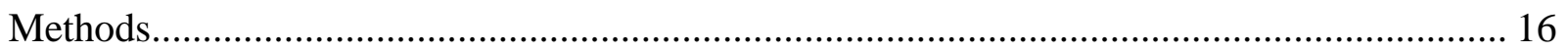

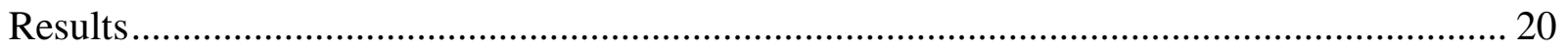

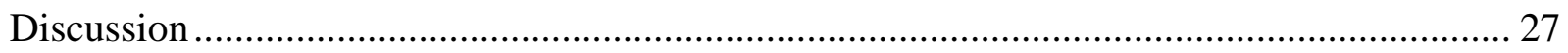

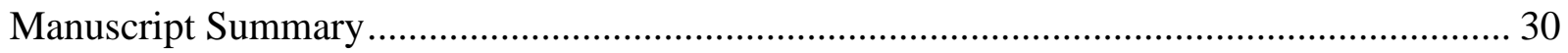


Chapter 4 : Extended Methods and Additional Data Set .................................................. 32

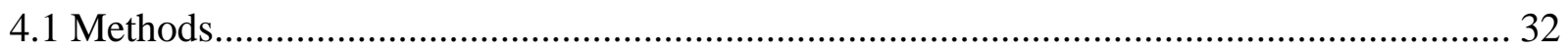

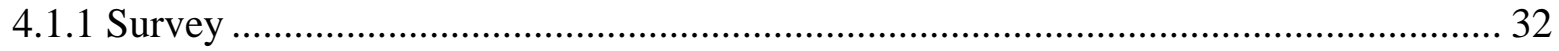

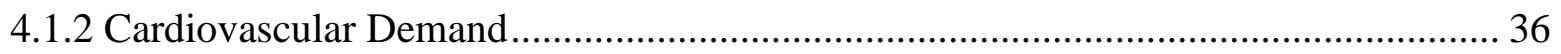

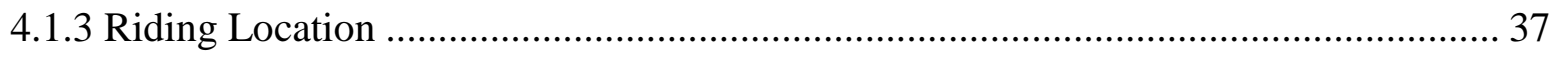

4.1.4 Statistical Analyses ...................................................................................... 38

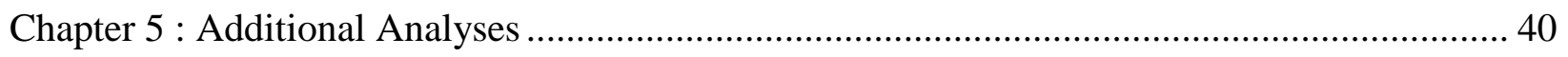

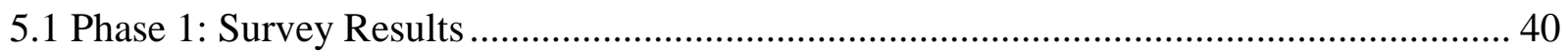

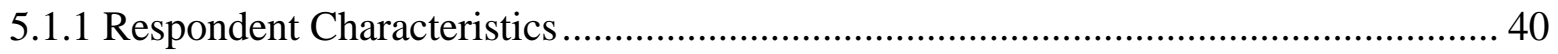

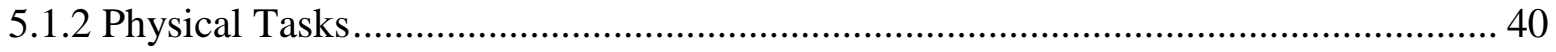

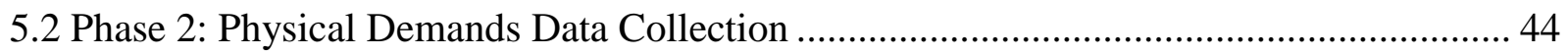

5.2.1 Subject and Riding Characteristic ................................................................ 44

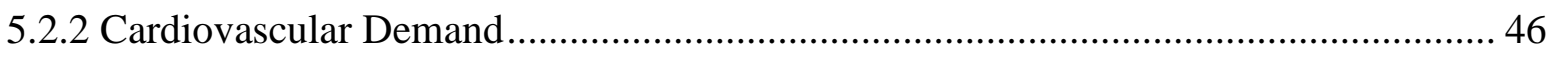

5.2.3 Muscular Strength \& Power......................................................................... 49

5.2.4 Body Position while Riding ....................................................................... 49

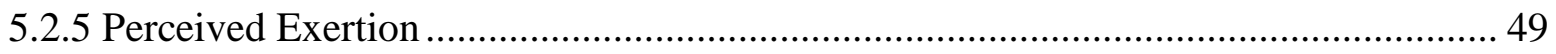

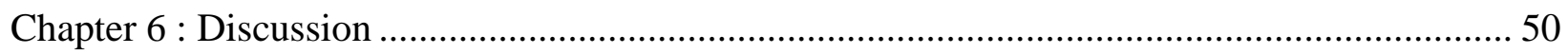

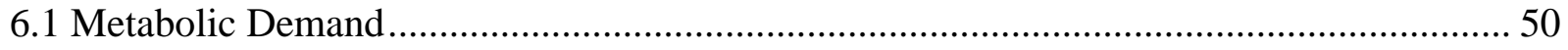

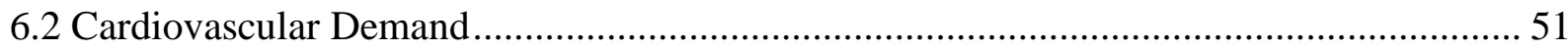

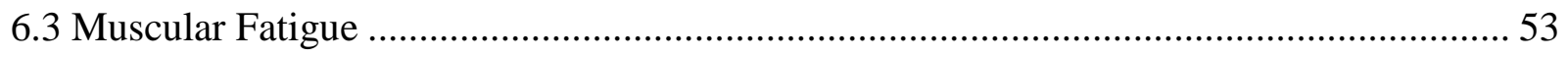

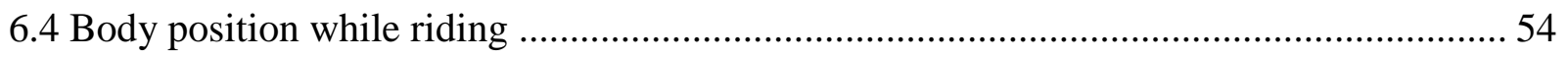

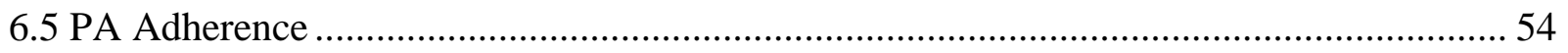

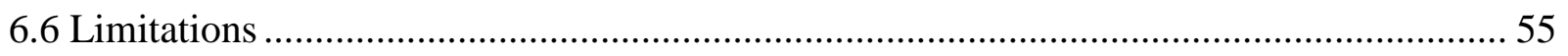

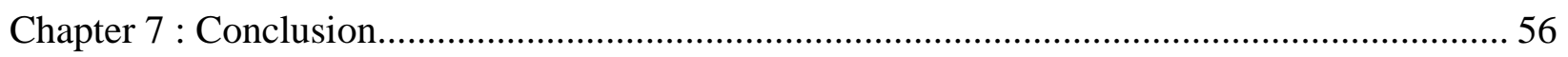

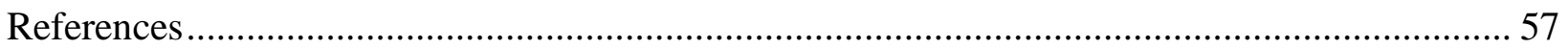




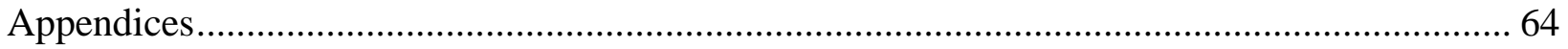




\section{LIST OF TABLES}

Table 1. Manuscript Anthropometric and Cardiovascular Characteristics ............................... 22

Table 2. Aerobic and Cardiovascular Demands During Snowmobile Riding ........................... 25

Table 3. Anthropometric and Cardiovascular Characteristics of Backcountry Riders ............... 45

Table 4. Ride Characteristics of All Locations .................................................................. 46

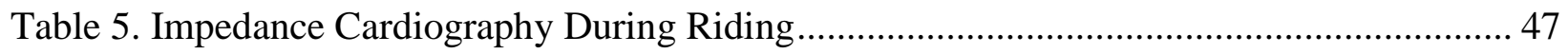

Table 6. HR-Matched Comparison of Snowmobile Riding to Exercise................................... 48 


\section{LIST OF FIGURES}

Figure 1. Portable Metabolic Analyzer ....................................................................... 17

Figure 2. Time Spent Riding Specific Terrain Features .................................................. 20

Figure 3. Cumulative Percentage of a Ride at Different Intensities $\left(\% \mathrm{VO}_{2} \mathrm{R}\right) \ldots \ldots \ldots \ldots \ldots \ldots \ldots \ldots . \ldots \ldots$

Figure 4. Conceptual and Measured HR Inflation .......................................................... 26

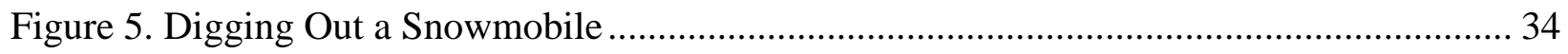

Figure 6. Terrain-based Differences in Snowmobiles ........................................................ 35

Figure 7. Electrode Placement for Impedance Cardiography ............................................. 36

Figure 8. Topographical Map of Representative Rides .................................................... 38

Figure 9. Difference between Groomed and Non-Groomed Trails ....................................... 41

Figure 10. The Second Most Demanding Task Associated with Snowmobiling ...................... 43 


\section{LIST OF ABBREVIATIONS}

1 - up - a single rider on a snowmobile

2 - up - two riders on a snowmobile, one driver and a passenger riding seated behind the driver ACSM - the American College of Sports Medicine

BCR - Backcountry

BPM - Beats per min

$\mathrm{Q}-$ Cardiac output

CSEP - Canadian Society for Exercise Physiology

EDFR - Early diastolic filling ratio

EDV - End diastolic volume

$\mathrm{EF}-$ Ejection fraction

FL - Flatland terrain

GXT - Graded Exercise Test

HR - Heart rate

MAP - Mean arterial pressure

METs - metabolic equivalent

MN - Mountain terrain

NEAT - Non-exercise activity thermogenesis

OHV - Off-highway vehicle

PA - Physical Activity

RPE - Rating of perceived exertion

SV - Stroke volume

VET - Ventricular ejection time

$\mathrm{VO}_{2} \mathrm{R}-\mathrm{VO}_{2}$ reserve

WHO - World Health Organization 


\section{LIST OF APPENDICES}

Appendix A: REB Certification of Approval of Research .................................................. 64

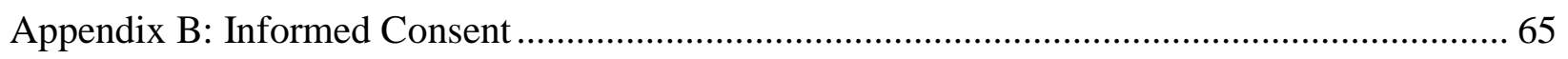

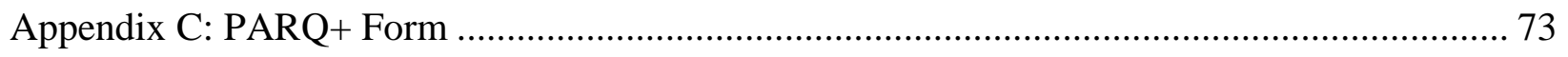

Appendix D: Snowmobile Survey \& Survey Consent................................................... 76 


\section{Chapter 1: Literature Review}

\subsection{Physical Activity}

Physical activity (PA) is defined as the expenditure of energy by skeletal muscles to produce bodily movement ${ }^{1}$. From this, exercise is defined as a physical activity that is planned, structured, and repetitive ${ }^{1}$. The ability to perform PA and the attributes acquired from bouts of PA and exercise, determine an individual's physical fitness. Prior to the advent of technology, hunter-gatherer and nomadic lifestyles provided the majority of human's PA and exercise requirements to ensure survival. Technology has now shifted the paradigm of PA as a means of survival to a lifestyle choice, but despite this shift in paradigm, PA is still widely regarded as a valued and essential aspect of optimal health and wellness ${ }^{2}$. Achieving the recommended volume and intensity of PA can elicit a wide range of beneficial physiological responses including a decreased risk of cardiovascular disease ${ }^{3}$, diabetes ${ }^{4}$, cancer ${ }^{5}$, and impaired cognitive/physical function during later adulthood ${ }^{6}$.

The benefits of PA are so widely valued that numerous national and world organizations have set out PA-specific guidelines to ensure that individuals of all ages obtain sufficient PA. For example, The American College of Sports Medicine ${ }^{7}$, the Canadian Society for Exercise Physiology ${ }^{8}$, and the World Health Organization ${ }^{9}$ recommend that adults engage in at least 150 minutes of moderate intensity physical activity per week to maintain a healthy lifestyle.

\subsubsection{Sedentary Behaviors \& Consequences}

While the benefits of PA are recognized and valued, there is a subset of the population who are not achieving minimum guidelines of PA, and this subset of physically inactive individuals is growing exponentially. Physical inactivity is becoming an increasingly alarming global pandemic, with 1 in 4 adults ${ }^{10}$, and 4 out of 5 adolescents ${ }^{11}$, not obtaining sufficient PA. Physical inactivity significantly increases major health care costs and was associated with 53.8 billion dollars globally for health care in 2013, of which 13.7 billion dollars was due to productivity lost due to death ${ }^{12}$. 
In North America, failing to meet activity guidelines or low PA is estimated to be responsible for $15 \%$ of the newly diagnosed chronic health issues each year ${ }^{13}$. Those chronic diseases include breast cancer, colon cancer, coronary heart disease, hypertension, osteoporosis, stroke, and type 2 diabetes mellitus ${ }^{14}$. Lack of PA is also linked to the development of arthritis, obesity, physical disabilities, psychological disorders and sarcopenia ${ }^{14}$. Approximately 16 million North American adolescents and adults have low cardiorespiratory fitness, which is associated with higher body mass index (BMI), waist circumference, total cholesterol, and blood pressure than their physically fit counterparts, all of which puts individuals at a greater risk of cardiovascular disease ${ }^{15}$. Those with lower fitness levels were 2 to 4 times more likely to be overweight or obese, thus increasing the risk of developing metabolic syndrome ${ }^{15}$.

Some major limiting factors to adequate PA are perceived barriers that reduce an individual's access or motivation to modes of physical activity. Some of the potential barriers that could hinder an individual from achieving sufficient PA time include lack of: time, motivation, enjoyment of participation, knowledge, confidence, goal setting skills, social support, physical coordination, access, energy, fear of injury, travel, and family obligations ${ }^{16}$. Enjoyment of participation in PA is one of many barriers which can be easily modified, and yet requires that the individual understand what constitutes PA and exercise. If an individual does not prefer traditional forms of exercise (e.g. treadmill running), the knowledge that they could potentially accumulate PA time in other forms could assist in PA adherence, and thus improvements in health.

Compared to the spring and summer seasons, the North American population tends to decrease weekly recreational energy expenditure by $15-20 \%$ in the winter ${ }^{17}$. Insufficient PA time is exacerbated in winter, as literature has demonstrated that low temperature, high precipitation, and reduced daylight hours are barriers highly correlated to physical inactivity, especially when the most common physical activity across all populations is walking ${ }^{18}$. As a result, it is likely that many individuals fail to meet recommended guidelines for the quality and quantity of physical activity required to maintain health and fitness, during the winter months. 


\subsection{Snowmobiling as a Physical Activity Alternative}

Snowmobile riding may offer a potential alternative mode of recreational activity that can be performed during the winter months. In Canada, there are already over 1.5 million families involved in snowmobiling each year, and over $120,000 \mathrm{~km}$ of dedicated trails ${ }^{19}$. Snowmobiling can be a diverse activity, as applications range from pure recreation to transportation, both as a primary mode of transport and for occupational purposes (law enforcement, national parks, rangers, etc.). Snowmobile enthusiasts commonly report engagement in snowmobiling for the opportunity to explore nature with friends and family, while obtaining the benefits of participation in a physical activity ${ }^{20}$. As snowmobiling has a general appeal for being accessible to all ages and provides opportunities to explore nature, it is possible that participation in this outdoor recreational activity could contribute to a greater accumulation of physically active time.

Since snowmobiling is traditionally viewed as a seated activity, it may be assumed that it is a light-intensity PA. Even if this is determined to be correct, there is still potential for health benefits with light-intensity PA. Short bouts ( $<10 \mathrm{~min})$ of light PA are associated with lowered

adiposity and consequently lowered risk of metabolic disease ${ }^{20}$. This is promising for sedentary or older individuals, who may not be capable of longer or more intense bouts of PA ${ }^{20}$. In a previous investigation that examined the benefits of an 8-week walking program, there were significant reductions in serum cholesterol and increased high-density lipoprotein, both of which are associated with decreasing cardiovascular risk ${ }^{21}$. As a standard winter season in North America is much longer than 8 weeks and dependent on geographic location, snowmobiling over a season could have beneficial cardiovascular effects if it is categorized as light-intensity exercise or greater. Regardless of intensity, increasing the total amount of PA is critical to improve health. As overweight or obese individuals generally prefer sedentary behaviours ${ }^{22}$, these individuals might be attracted to snowmobiling as an alternative form of PA.

Intermittent standing while riding a snowmobile is a common response for riders to navigate terrain perturbations and allows for better manipulation of weight distribution. Thus, although snowmobiling may be regarded as a seated PA, there are recurrent bouts of standing. During occupational desk work, even 10 sit to stand to sit transitions have been shown to 
increase metabolic rate, which translates to an additional 3.2 kcals burned ${ }^{23}$. Improved glucose and insulin responses have been observed in non-diabetic sedentary obese or overweight adults when comparing 7 hours of non-interrupted sitting to 5 hours of sitting with 2-minute light or moderate intensity walking bouts every 20 minutes ${ }^{24}$. Similarly, intermittent periods of light intensity (45-60\% $\mathrm{VO}_{2} \max$ ) activity during sedentary time improved glucose clearance, which was observed in healthy normal weight individuals, independently of BMI ${ }^{25}$. As such, standing in response to terrain perturbations, or as a riding style, could likely contribute to additional activity or health benefits during snowmobile riding.

In addition to the intermittent transitions from sitting to standing, there are other tasks associated with snowmobile riding that might encourage or require an individual to be more active. Some of the tasks that occur in preparation for, during, or after a snowmobile ride include; unhitching or hitching a trailer, unloading or loading a trailer, digging out a stuck snowmobile, lifting the back end of a snowmobile to loosen snow or ice from the track, tipping the snowmobile for repairs, and clearing brush from the path ahead. These types of activities might be beneficial as they would increase non-exercise activity thermogenesis (NEAT) by requiring the individual to stand up, lift, or walk in order to continue with their ride, which would increase the total daily energy expenditure and could assist in a positive change in weight or health ${ }^{26}$.

According to the Compendium of Physical Activities, snowmobiling is rated as a 3.5 METs ${ }^{27}$. Metabolic equivalents, or METs, represent an estimation of the oxygen cost by a factor of rest, with 1 MET being equal to rest, and rest being approximately $3.5 \mathrm{ml} \cdot \mathrm{kg}^{-1} \cdot \mathrm{min}^{-1}{ }^{1}$. It is recognized that individual differences in metabolic rate may exist at rest ${ }^{28,29}$; and as such METs may vary in their accuracy across a population. That said, as a construct, METs are still a valuable tool for physical activity classification and estimating overall energy expenditure. In the present thesis, PA is thus expressed as both an oxygen consumption and MET value, to allow for comparison with medical literature, and normative data such as that contained in the Compendium of Physical Activity ${ }^{27}$. From the traditional views of snowmobiling, this low physical activity intensity rating is logical if snowmobiling only required sitting. However, from the above, it is apparent that snowmobiling may be a much more dynamic and physically 
demanding activity than previously thought. Some of the factors that would influence the physical demands are standing or shifting weight in response to terrain features, maintaining posture and balance while riding uneven terrain, maintaining a strong grip on the handlebars and the peripheral tasks associated with normal riding (moving brush from path ahead, lifting the end of a snowmobile for repairs or loosening ice, digging out, etc.).

An important factor to be taken into consideration for potential differences in the energy cost of navigating different terrains is the necessity of moving one's centre of mass to maintain balance. Shifting of one's weight forward would be more readily used for steep hill or mountain climbing to maintain the rider's balance. Similarly, shifting weight into a corner could be more physically demanding depending on how tightly that the rider is trying to turn or how deep the snow is. A tighter turn would require the rider to shift their centre of mass more to avoid tipping the snowmobile. Mountain snowmobiling, or deep snow riding, would hypothetically be more physically demanding, because these types of riding requires the recruitment of larger muscle groups to complete the same basic tasks, such as hill climbing or turning tasks than a rider on flatter ground. Turning a snowmobile in deep powder involves greater shifting of body weight because the skis do not produce a sufficient opposing force to redirect the path of the snowmobile on loose powder snow. Thus, a more effective method of turning is to use the underside of the snowmobile like the hull of a boat, which requires the snowmobile to be tipped sideways so that a single ski is on the ground. Considering that many snowmobiles weigh upwards of $400 \mathrm{lb}$. this can represent a significant physical challenge, that requires strength as well as skill. There could also be a significant difference in the physical demands of mountain steering versus flatland steering as a rider may have to perform more exaggerated full body turns in deep snow or uphill than when riding on flat land. Riding uneven terrain could also add to the physical demands as the rider has to expend energy and use their musculature to maintain their balance and posture. It is important to note that the current MET value for snowmobiling is an estimation that is based on epidemiological studies, but there is currently no snowmobile literature specifically measuring the metabolic cost of this activity. All of the above measures should be accounted for if directly measuring the physical demands of snowmobiling. 


\subsubsection{Riding-based Activity Comparison}

The potential PA-mediated benefits of snowmobiling that are often discussed by proponents of the sport are predicated on the fact that snowmobile riding is indeed an activity of sufficient exercise intensity to fall within accepted guidelines, yet this fact has not yet been established. Inferences can be made to determine potential demand and associated benefits by comparing to other riding-based activities that have been investigated, such as horseback, ATV and off-road motorcycle riding.

Similar to snowmobiling and other riding-based activities, horseback riding involves constantly varying speeds based on terrain or tasks and gaits that affect the metabolic demand of the rider. In horseback riding, oxygen consumption was measured to be between 40 to $80 \%$ of the maximal aerobic capacity of the rider ${ }^{30}$. It was classified as a moderate intensity exercise with a 3-6 METs range as recorded in female recreational riders ${ }^{31}$. The large range in METs and percentage of maximal aerobic capacity, demonstrates that the demand varies, possibly due to the combined factors of speed and task. Due to the variation in exercise intensity over the course of a horseback ride, we expect that snowmobiling will also be varied in exercise intensity as there are tasks, terrain features or speeds that are constantly changing during a ride and could contribute to the overall metabolic demand.

This trend has also been observed in ATV and off-road motorcycle riding, which was demonstrated to increase oxygen consumption 3.5 and 6-fold, respectively, above rest (METs) ${ }^{32}$. This level of exertion is classified as a moderate intensity activity by the American College of Sports Medicine (ACSM) ${ }^{32,33}$. These activities are comparable to snowmobile riding, as each activity involves the use of an engine-based machine for recreational transportation. Another similar component across snowmobiling and other OHV riding is the muscular demand of isometric handlebar gripping ${ }^{32,34}$. Increased forearm flexor activation has been observed during recreational and competitive motocross riding, suggesting that handlebar gripping may induce notable fatigue through this increased activation. In a study by Burr et al. (2010), a significant decrease in grip strength was observed in both forearms post off-road motorcycle riding. The above seems to suggest that there may be a muscular endurance component associated with snowmobile riding. Furthermore, it is well known that increases in grip strength is associated 
with acute and chronic alterations in vascular tone and blood pressure ${ }^{35}$, which suggests that this may be an important area to confirm for its potential implications on health. Based on the above examples, certain parallels can be drawn about snowmobiling through other riding-based physical activities, although it is difficult to make direct comparisons without specific quantification of the metabolic demand.

In the early $20^{\text {th }}$ century, Douglas bags were used to collect expired gases for analysis and quantification of the aerobic demand in challenging environments ${ }^{36}$. While feasible, this method was not ideal as the bag required consistent changing (especially with more vigorous exercise and high ventilation rates), and required significant laboratory skill for gas sampling and cleaning ${ }^{36}$. Indeed, in the early riding-based literature, aerobic demand was measured directly using Douglas bags as per Westerling (1983) who examined the physical demands of horseback riding. With technological advancements, reliable and efficient portable electronic analyzers have further improved the accuracy and reliability of the measurement of oxygen consumption 37 .

As opposed to the measurement of expired gases, estimation of aerobic demand can also be accomplished through surrogate measures of physical demand using non-invasive techniques like HR monitoring, which is relatively inexpensive and requires few technical skills. This estimation is based on the linear relationship between $\mathrm{HR}$ and $\mathrm{VO}_{2}$.However, there are many other factors that can influence HR independently of metabolic demand ${ }^{1}$. Some factors include variations in ambient temperature, mental stress, hydration status, and humidity ${ }^{38}$. Off-road highway vehicle riding has been shown to present a challenge physiologically, but also psychologically, with a number of studies demonstrating an increase in mental stress or markers of stress, like catecholamines or glucocorticoids, in response to OHV riding ${ }^{39-41}$. Since mental stress can cause variations in $\mathrm{HR}^{42}$, it is likely that mental stress could be further influencing $\mathrm{HR}$ during $\mathrm{OHV}$ riding outside of the normal exercise response. In support of this, it was observed that when matched for aerobic demand, there was an increase in OHV Riding HR ${ }^{32}$. This further emphasizes the need for concomitant oxygen uptake and HR monitoring in current $\mathrm{OHV}$ research. 


\subsubsection{Altered Cardiovascular Response to Exercise}

Recent OHV research has sought to expand the measurement of physical demand in adventure sport activity by exploring the demands imposed on the cardiovascular system. Direct hemodynamic measures in humans can be made through invasive catheter insertions or using imaging techniques like echocardiography. A major limitation to measuring hemodynamics via catheterization is that it is very invasive and can only be done in a hospital, thus it is highly impractical in a laboratory or field-based setting. Measuring hemodynamics via ultrasound is also limited by the inability to measure exercise response due to the artifact of movement ${ }^{43}$. Impedance cardiography offers a non-invasive measure of total electrical conductivity within the thorax, and its fluctuations in time ${ }^{44}$, thus giving insight into exercising hemodynamics. It is accepted that variations in the ability to pass a low-grade electrical signal down the aorta and through the thorax represent differences in blood volume, and this can be combined with ECG tracings and used to model cardiovascular function (see section 4.1.2). Impedance cardiography has proven to be a reliable and strongly correlated method of estimating cardiac output based on comparisons to direct cardiac output measurements using thermodilution ${ }^{44-46}$.

Using impedance cardiography, Sanna et al. (2017) monitored fifteen skilled Enduro motorcycle riders while they participated in a 10-minute riding session. It was observed that this type of riding was a significant challenge to the cardiovascular system, measured as increases in $\mathrm{SV}$ and $\mathrm{Q}^{47}$. One major limitation of that study is that the riding cardiovascular response was not compared to more traditional exercise, as the noted increase in cardiovascular work could be a product of regular exercise rather than specific to OHV riding. Although this cardiovascular response would not add additional demands to the activity, an understanding of the specific influence of riding on cardiovascular function, or dysfunction, allows for an appreciation of the activity stress at a mechanistic level, and may give insight into the expected physiological adaptations, and appropriateness of the activity for different populations.

Sympathetic activation is a normal exercise response and can also be induced through the release of neurohormonal transmitters associated with the stress and excitement of riding. During regular exercise, sympathetic activation initiates increases in HR, enhancements in contractility, and increases vascular resistance to inactive or non-vital organs to direct blood for working 
muscle perfusion ${ }^{48}$. During psychological stress, parasympathetic input withdraws from the heart while sympathetic activity and circulating catecholamines increase, which causes increases in $\mathrm{HR}^{49}$. OHV riding is a significant psychological stressor as noted by the increased levels of circulating catecholamines and glucocorticoids during riding ${ }^{39-41}$. Some studies have observed as much as a two-fold increase in post-riding catecholamines after simulated or competitive racing scenarios ${ }^{40,41}$. More specifically, Schwaberger et al. (1987) observed that this increase in circulating catecholamines was significantly higher than the normative exercise response to maximal cycle ergometry. This suggests that there may be an additional sympathetic stimulus while riding that contributes to the unique cardiovascular response of OHV-related activities.

It has been observed that there are $50 \%$ more cases of acute myocardial injury reported during winter ${ }^{50}$. This increase in cardiovascular events has been observed mostly in the days following major snowfall and has been attributed to the over-exertion of snow-shoveling ${ }^{51}$. Cold air exposure also increases sympathetic activation via an increase in plasma norepinephrine as observed in healthy subjects who were exposed to roughly $7^{\circ} \mathrm{C}$ air ${ }^{52}$. The thermoregulatory response to cold is to vasoconstrict the periphery to centralize blood flow in an attempt to conserve body temperature ${ }^{53}$. Cardiac work increases as the vasoconstriction causes an increase in blood pressure and plasma viscosity while decreasing plasma volume ${ }^{53}$. Since snowmobiling is a physical activity that takes place in winter, it is possible that this set of unique environmental stressors would similarly affect the cardiovascular system, thus it is an opportunity to investigate if the cardiovascular response to normal exercise is altered with participation in this activity. While all of these factors have the potential to occur during snowmobiling, which obviously takes place in a cold and snowy climate, it also is currently unclear whether cardiovascular physiology is affected as snowmobile riders have well-insulated gear.

Another potential explanation for an altered cardiovascular response is from a potential exercise pressor effect. This effect is driven by signals from the contracting muscle's metabolic and mechanical stressors, which can affect sympathetic nervous system output to ensure that the cardiovascular system provides the requisite blood flow to the active tissues ${ }^{48}$. Snowmobiling requires riders to constantly grip the handlebars in order to maintain control and not fall from the machine. During an isometric contraction, active muscle fibres swell and stiffen, which increases 
intramuscular pressure, and this increases the pressure on the blood vessels ${ }^{54}$. The resulting increase in total peripheral resistance causes an increased activation of the sympathetic nervous system that induces inotropy and chronotropy to overcome the intramuscular pressure and maintain blood flow ${ }^{54}$.

\subsubsection{Potential Mental Health Benefits of Participation}

It is important to note that health is a multi-faceted concept that is more than a lack of disease or injury. Health is defined by the World Health Organization (WHO) as "a state of complete physical, mental, and social well-being and not merely the absence of disease or infirmity" 55 . It should be recognized that there could also be potential mental health benefits to snowmobiling. Outdoor physical activity is associated with decreased mental fatigue ${ }^{56}$, decreased stress levels ${ }^{57}$, improved self-esteem ${ }^{58}$, improved social networking ${ }^{59}$, and a sense of connection with nature ${ }^{59}$. Snowmobiling presents a unique activity that could potentially contribute to the accumulation of physical activity time in addition to providing an opportunity to explore nature while in a social setting.

Urban environments heavily tax our attention with additional, frequent, and irrelevant stimuli that lead to cognitive fatigue, which may be linked to increased rates of mental illness, including anxiety and depression ${ }^{60}$. Physical activity in natural environments can decrease a variety of mental illness symptoms, including rumination, negative moods, sympathetic nervous activity, and subgenual prefrontal cortex activity, which are not observed when the same activity is performed in an urban environment ${ }^{60,61}$. This suggests that accessing natural settings may be integral for maintaining mental health, and outdoor activities like snowmobiling could be a good way to ensure exposure to nature.

Avid snowmobile riders engage in this outdoor physical activity as an opportunity to gain a sense of camaraderie and build social ties with friends or family ${ }^{62}$, which can contribute positively to mental health ${ }^{63}$. Loneliness, a side effect of social isolation, is experienced by $10 \%$ of the population, and is associated with depression, generalized anxiety disorder and suicidal thoughts ${ }^{64}$. It is also a risk factor for all-cause mortality, independent of depression, socioeconomic status, and other mortality risk factors ${ }^{65}$. However, quality social interactions that 
occur during exercise influence an individual's perception of social support, and decrease feelings of loneliness ${ }^{66}$. Intervention studies have found favorable effects of physical activity programs on loneliness ${ }^{67-70}$, and in some cases exercise was more beneficial versus similarly social, but inactive programs ${ }^{68}$. This suggests that social connections made during physical activity can be perceived as more positive and meaningful than other relationships. Meaningful relationships that are created and maintained during social physical activities, such as snowmobiling, could therefore combat social isolation and enhance a person's physical and mental well-being.

\subsubsection{Health \& Safety Considerations}

While there is potential for snowmobile riding to be beneficial to physical and mental health, it is prudent to consider all aspects of health surrounding the activity. In snowmobiling culture, it is possible that there are detracting factors that reduce the overall benefit of the activity. Like any other member of the population, who may or may not be physically active, the health status of a snowmobiler will be determined by a complex balance of lifestyle factors/choices including things such as socioeconomic status, marital status, physical activity level, diet, alcohol use and risky behaviours. It is important to note that this is not an exhaustive list, nor are these factors mutually exclusive. If a snowmobiler engages in a several hour ride and over-consumes a large quantity of calories post-ride, this could mitigate the caloric energy. As such, the value of the activity must be considered in context. Anecdotal reports of lifestyle choices surrounding the sport suggests that factors such as alcohol consumption and smoking are two major factors that could negatively influence health/ detract from potential benefits of activity, but it is important to note that this was not specifically studied.

In terms of safety, riders determine the location and conditions of riding, which is similar to participating in other off-road vehicle riding. These types of vehicles are often portrayed as toys to individuals under 18 years of age, which undermines the level of safety considerations needed for operation ${ }^{71}$, and legislation regarding snowmobile operation is not standardized across provinces. Even something as intuitive as helmet use is not mandatory in the province of British Columbia, and minimum driver age varies across all provinces, which can depend on whether the rider is on private property ${ }^{72}$. The fatality rate for snowmobilers was 0.2 per 
100,000 individuals in 2010, and there were higher odds of being fatally injured while snowmobiling than ATV or dirt-bike riding ${ }^{71}$. The most common mechanisms of fatal injury while snowmobiling are crashing into a fixed object ( $47.7 \%$ of all fatal injuries), and submersion in water $(16.6 \%)^{71}$.

Of the fatal injuries studied, $65.9 \%$ of snowmobile operators tested positive for alcohol impairment, and $80.4 \%$ of those who tested positively for alcohol had a blood alcohol content of at least $0.08 \%$, while $47.5 \%$ had a blood alcohol content over $0.16^{71}$. It seems like the combination of riding and alcohol consumption creates a riding environment where riders are less inhibited and more likely to engage in risky behaviours. A particularly risky snowmobile behaviour is a trend called high-marking, where individuals will compete with their riding party to determine who can climb to the highest point of a slope, and this particular activity has a high chance of causing an avalanche ${ }^{73}$. For winter related injury, snowmobiling incidents represent the most frequent cause of injury (40\%) in comparison to other winter sports like snowboarding (24\%), skiing (19\%), hockey (11\%), or ice-skating (3\%) ${ }^{72}$. In a study by the Canadian Institute of Health Information (2007), the most common form of snowmobiling injuries were lower limb fractures $(35.5 \%)$, with a $73.5 \%$ chance that the driver was injured rather than the passenger. The second most common injury was fractures to the ribs, sternum or vertebrae (28.1\%), followed by head injuries $(15.8 \%)^{72}$.

A potential snowmobile rider must consider the potential benefits and risks associated with snowmobiling, in order to make an informed decision regarding participation. Snowmobiling is inherently varied by differing riding styles, riding terrain or riding conditions, thus the risks can vary depending on each rider's commitment to their own safety and that of others. Diet and other individual lifestyles (alcohol consumption, smoking, etc.) may potentially detract from the health benefits of activity. It is important to consider all aspects of the activity to create a complete overview, to determine if snowmobiling is the right recreational activity for a person's lifestyle and PA needs. It is recognized that there are many aspects of snowmobiling that must be considered, but this thesis is primarily concerned with the physical fitness and demand perspective. 


\section{Chapter 2: Purpose}

Purpose: To evaluate scientifically the physiological demand of participation in recreational snowmobile riding. Specifically, we aim to determine the cardiorespiratory and strength demands of snowmobile riding across mountainous and flat terrain, in order to characterize the overall physical demand of snowmobiling.

Primary Hypothesis: Snowmobile riding will be associated with an average physical demand that is significantly above resting, and which falls into the general classification of moderatevigorous physical activity that is associated with positive health and fitness changes occur. As is consistent with other riding activities, it is hypothesized that the majority of time spent riding a snowmobile will be in the "moderate" intensity zone (40-65\% $\left.\mathrm{VO}_{2} \mathrm{R}\right)$, with infrequent excursions into "vigorous" activity $\left(>85 \% \mathrm{VO}_{2} \mathrm{R}\right)$.

Secondary Hypothesis: Substantial differences will exist according to the terrain type. Those differences will dictate changes in riding style and physical demand between trail riding and off-trail riding. 
The following is presented in manuscript style in preparation for publication. 


\section{Chapter 3: Manuscript}

\section{Background}

Physical activity (PA) is a critical component of a healthy balanced lifestyle. When accumulated at the recommended volume and intensity, PA is associated with benefits such as a decrease in the risk of: cardiovascular disease ${ }^{3}$, diabetes ${ }^{4}$, cancer ${ }^{5}$, and impaired cognitive/physical function during later adulthood ${ }^{4}$. Canadian physical inactivity data suggest a large burden on the health care system as $85 \%$ of the population do not achieve the recommended quantity of physical activity, which is associated with 6.8 billion dollars or $3.7 \%$ of the total health care costs ${ }^{75}$. The issue of insufficient PA is especially exacerbated during the winter season as energy expenditure decreases by $15-20 \%{ }^{17}$, due to barriers such as low temperature, high precipitation, and reduced daylight hours ${ }^{18}$. As a result, many individuals fail to meet recommended guidelines.

Snowmobile riding is a popular recreational winter activity in many parts of the world. It is possible that recreational snowmobiling could be of sufficient intensity, frequency, and duration to contribute to a greater accumulation of PA to meet recommended guidelines and help to offset winter-time physical inactivity, but this has not been established with rigorous scientific investigation. Snowmobile riding clearly differs from more traditional PA and exercise because it uses a gas-powered motor. However, parallels can be drawn to other externally powered individual activities (i.e. equestrian and off-road motorsports) that involve coordinating one's physical movements to adjust to changes in speed and terrain. These activities have previously been classified as moderately intense exercise (3-6 METs) ${ }^{31,33}$.

The purpose of this study was to evaluate the physiological demand of recreational snowmobile riding using habitual riders participating under typical riding conditions. Given the similarities to sports like equestrian and off-road vehicle riding, it was hypothesized that snowmobile riding would have a moderate intensity metabolic demand. More specifically, we hypothesized that the majority of a ride would be of "moderate" intensity, with infrequent excursions into "vigorous" activity. Our secondary hypothesis was that substantial differences in 
physical demand would exist according to the characteristics of a typical ride, with consideration of factors such as terrain type, trail grooming, vehicle style, and riding technique.

\section{Methods}

\section{Phase 1- Definition of a Typical PA Exposure}

To define the "typical" ride, a survey was distributed electronically to habitual snowmobile riders in Canada and the United States $(n=4,015)$ identified through national, provincial/state and local organizations. Habitual participation was defined as having at least one full year of snowmobile experience, with an average riding frequency of at least once per week. The survey inquired about basic demographics, years of experience, perceptions of the physical tasks, and the duration of a typical ride. The survey also sought to define terrain features associated with normal riding, the perceived physical demand of riding-specific tasks, and the frequency at which those tasks/features occur. In the end, two courses were designed, one for flatland (FL) and one for mountainous (MN) riding.

\section{Phase 2 - Physical Demands Analysis}

As it is unrealistic to collect physiological data over the course of a multi-hour ride, survey data on terrain, geographic location, tasks encountered, and frequency of exposures during riding was used to create a representative scaled course ( 20 min to traverse, working within the confines of terrain). Content matter experts (local professional snowmobile tour guides and experienced snowmobile riders) were used to design representative trails. All testing took place in either eastern (Haliburton, Ontario) or western Canada, (Revelstoke, British Columbia) with an ambient temperature of $1 \pm 1^{\circ} \mathrm{C}$ (range $=-10^{\circ} \mathrm{C}$ to $7^{\circ} \mathrm{C}$ ) and $4 \pm 1^{\circ} \mathrm{C}$ (range $=1{ }^{\circ} \mathrm{C}$ to $6^{\circ} \mathrm{C}$ ) respectively.

Participants: Recreational snowmobile riders $(n=40)$ between 18-64 years of age were recruited locally at each testing location ( $F L, n=19 ; M N, n=21)$ through the Canadian Council of Snowmobile Organizations (CCSO) and local snowmobile clubs. Before engaging in riding, all participants had anthropometrics and resting blood pressure measured. For accommodation and safety purposes, all riders were led through the representative trails at slow speed prior to the 
test. Riders were asked to use their own riding gear (gloves, jacket etc.) and were provided a helmet to account for fitting the mouthpiece used to collect metabolic data (Figure 1). During the representative rides, participants were specifically instructed to ride in a manner which as closely as possible represented how they would typically ride. Specific limitations on speed, technique and riding style were not imposed. This study was approved by the institutional Research Ethics Review board and all participants provided written informed consent.
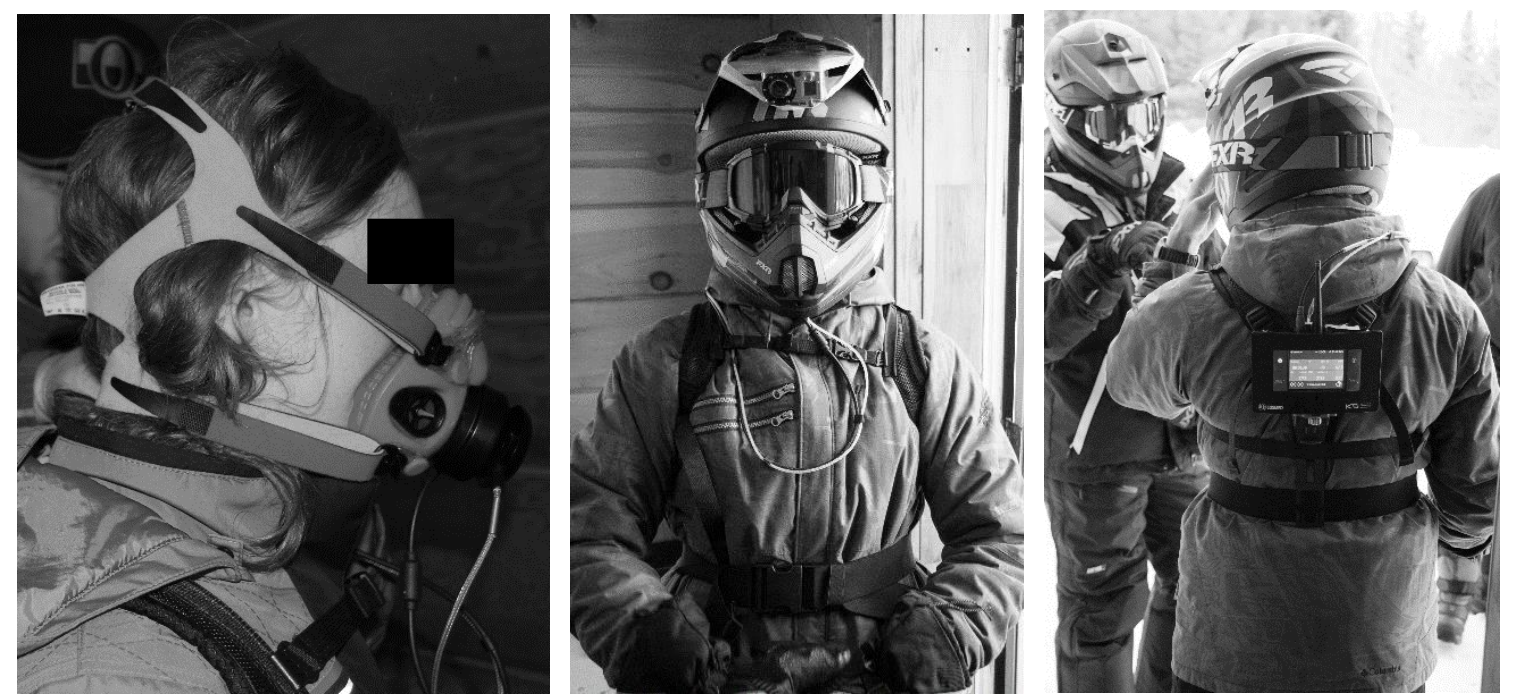

Figure 1. Metabolic monitoring during a representative ride, demonstrating the K5 analyzer facemask (left), the sampling lines protruding from under the helmet (center), and the K5 on the backpack mount (right).

Metabolic Demand: The cardiorespiratory response to snowmobile riding was quantified using a portable metabolic system (Cosmed, K5; Rome, Italy) worn on a backpack mount with a facemask under the participant's helmet. At the beginning of each testing day, the metabolic computer was calibrated with known gas concentrations, then prior to each ride, ventilatory flow was calibrated using a 3L cylinder syringe. During data collection, the volume of expired air was measured using an optical turbine connected to the mask, while expired $\mathrm{O}_{2}$ and $\mathrm{CO}_{2}$ concentrations were measured via sampling lines that attach the facemask to the analyzer (Figure 5). Breath-by-breath data were recorded and uploaded for analysis after each test. Participants also wore a portable GPS watch/altimeter (Suunto, Ambit3 Sport; Vantaa, Finland) with concomitant HR monitoring to determine altitude, speed, and HR during the ride. 
The Borg 6-20 Rating of Perceived Exertion (RPE) scale was used to assess effort during the ride as well as during a subsequent graded exercise test (GXT) ${ }^{76}$. Participants reported the average perceived exertion during the ride (RPE avg), the least physically demanding part of the ride (RPE min) and the most physically demanding part of the ride (RPE max).

Following field testing, participants performed a graded $\mathrm{VO}_{2}$ max test on an electromagnetically braked cycle ergometer (Racermate, Velotron; Seattle, Wa) with expired gas measured using a laboratory grade analyzer (Cosmed, Quark; Rome, Italy). The test comprised of a linearly ramped protocol with constantly increasing resistance (1W every 2 seconds; participants started at either ), and was terminated if 2 or more of the following were met: heart rate or $\mathrm{O}_{2}$ consumption failed to increase with progressive workloads over 30 seconds $( \pm 2 \mathrm{bpm}$ and/or $\geq 50 \mathrm{~mL} / \mathrm{min})^{77}$; a rating of perceived exertion $(\mathrm{RPE})>17$ was reported; the participant's cadence dropped <45 revolutions/min; an RER > 1.15; or volitional fatigue was reached.

Outcomes from the laboratory test were used to draw comparisons to the snowmobile ride and allowed for the calculation of relative intensities, accounting for fitness. A participant-specific linear regression of $\mathrm{HR}$ and $\mathrm{VO}_{2}$ was generated from the exercise test to compare to the response while riding. Riding exertion, expressed as a percentage of $\mathrm{VO}_{2}$ reserve ${ }^{78}$, was calculated as the total amount of time spent at, or above, a zone associated with health benefits.

As HR is an increasingly accessible method to track exercise intensity, we also sought to determine its accuracy for assessing the physical demand of snowmobiling. Using the linear regression of $\mathrm{HR}$ and $\mathrm{VO}_{2}$ established during the GXT, the expected $\mathrm{HR}$ while riding was forecast using the riding $\mathrm{VO}_{2}$ and compared with the concurrently measured $\mathrm{HR}$

Muscular strength and power: Strength and power tests were used to assess changes in muscular strength/power output as a result of riding, which are indicative of fatigue. Measures of handgrip strength and maximal vertical jump were conducted before and immediately after snowmobile riding on the representative course, to analyze upper and lower body musculature involvement, respectively. Grip strength was selected because it is a reasonable surrogate of general muscular strength and endurance ${ }^{79}$, and was assessed using a standard dynamometer (Smedley, Stoelting Co; Wood Dale, IL) adjusted to the second knuckle. Using three trials for each hand, participants squeezed maximally with the extended arm away from the leg (45 
degrees) and the highest of trials from each limb was combined for analysis. Vertical jump height was assessed using a Vertec device (Sports Imports, Vertec; Hilliard, $\mathrm{OH}$ ) with the highest of 3 attempts used for analysis. The difference between standing reach and jump height was used to calculate vertical displacement and combined with body mass to calculate leg power via the Sayer's equation ${ }^{80}$.

Body position while riding: An ActivPAL ${ }^{\mathrm{TM}}$ (PAL Technologies Ltd., Glasgow, UK) device was used to determine the participant's postural adjustments throughout the ride. This device is a tri-axial inclinometer and accelerometer that is attached to the thigh via Tegaderm (3M Germany GmbH; Neuss, Germany), midway between the patella and greater trochanter. It is designed to use information from the acceleration and position of the thigh to differentiate sitting, standing and stepping, as well as the number of transitions between postures. Samples were collected every 15 seconds, recording time spent in different body positions (standing versus sitting) using an activity coded system. Jarring accelerations that occurred in the standing position, which would normally register as walking, were used to understand the influence of rough terrain perturbations that may affect the physicality of riding.

Statistical Analysis: Baseline participant characteristics (anthropometrics, age, fitness, riding experience), and qualities of the representative rides (total riding time, speed, altitude) as well as the perceptual and physiological responses of riders ( $\mathrm{HR}, \mathrm{VO}_{2}, \mathrm{RPE}$ and experience) were compared across testing locations using independent t-tests. Paired t-tests were used to determine if snowmobiling elicited significant fatigue in strength and power. Pearson correlation was used to determine if there was a relationship between HR inflation and riding intensity $\left(\% \mathrm{VO}_{2} \mathrm{max}\right)$, thus indicating whether riding intensity influenced the level of inflation. Pearson correlation was also used with perception of effort and age, experience, and speed to determine if these variables were associated with the snowmobile rider's perceptions of riding demand. Statistical analyses were conducted using SPSS software (version 25; IBM, Chicago, IL, USA), with an a priori alpha of $\mathrm{P} \leq 0.05$. 


\section{Results}

Survey Results: Given the variability of terrain that was reported from the survey, testing was designed for both FL and MN terrain. Based on the approximately 4000 survey responses received, the FL course was designed to encompass primarily groomed trails (70\% of total riding time) in contrast to the $\mathrm{MN}$ trail, which was designed around non-groomed trails (70\% of the riding time). Differences in the perceived physical demand of riding flat versus mountainous terrain were highlighted in the survey, thus confirming the need for further objective investigation into terrain-specific differences. Additional specifics of course design that followed from survey results are presented in Figure 2, which was adhered to as closely as possible. However, there was an unstructured component to the $\mathrm{MN}$ representative course that allowed participants to ride "off-trail" and engage in riding as they normally would while in deep powder to reflect realistic riding habits.
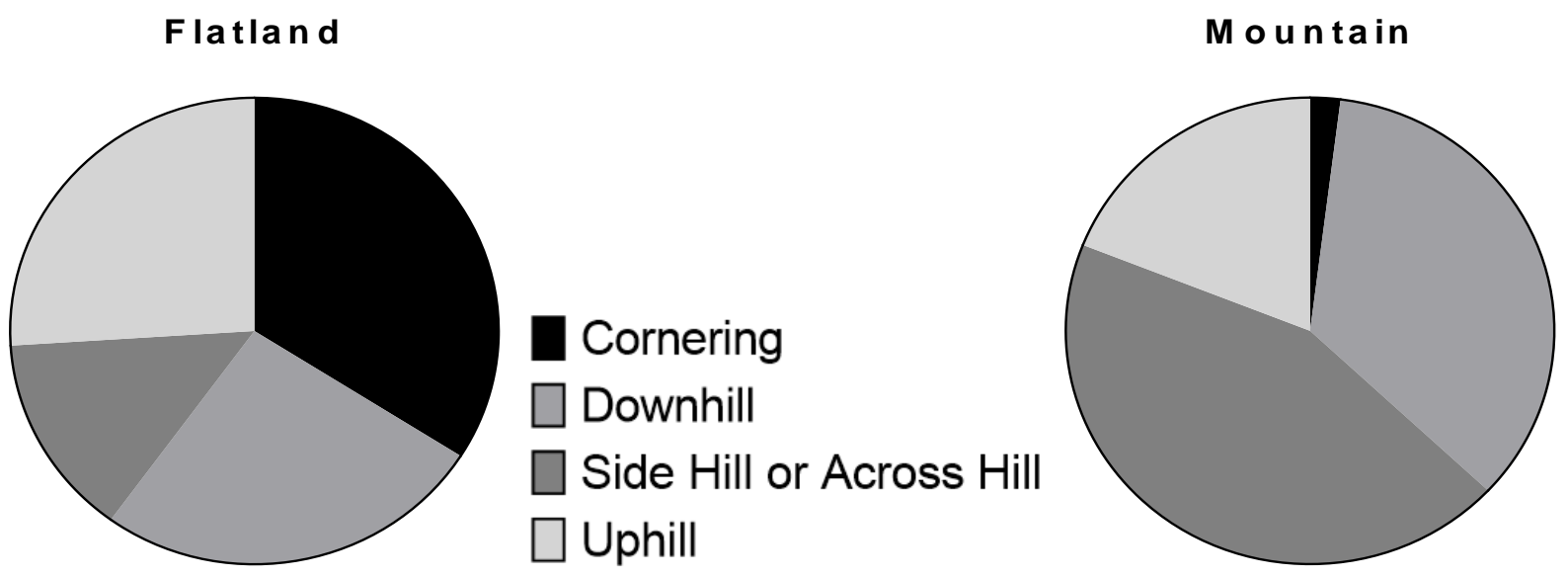

Figure 2. A graphical representation of the percentage of a total ride spent riding specific terrain features divided by location as determined by the survey of recreational snowmobilers.

The total time of data collection for the representative rides was $21 \pm 8$ minutes with a slight difference between locations (FL 18 \pm 4 mins vs MN 25 \pm 9 mins) owing to course restrictions of the specific geographic locations. As per the design, MN riders rode at 


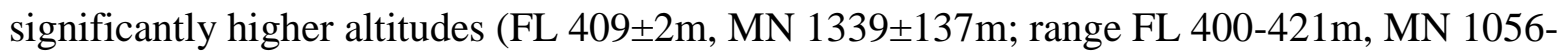
$1553 \mathrm{~m})$.

Riding Characteristics: Descriptive participant characteristics, combined and separated by testing location, are presented in Table 1. Comparing across locations, there were no differences in body composition, riding frequency or snowmobiling experience; however, there did appear to be variation in cardiovascular fitness amongst riders. There was a smaller number of female participants at the MN location (7/19 FL riders vs. 4/21 MN riders), which limited sex comparisons across terrains. 
Table 1. Anthropometric and resting cardiovascular characteristics of the snowmobile riders who participated in testing. Snowmobiling frequency and years of experience of the riders are also reported. Data expressed as means \pm SD.

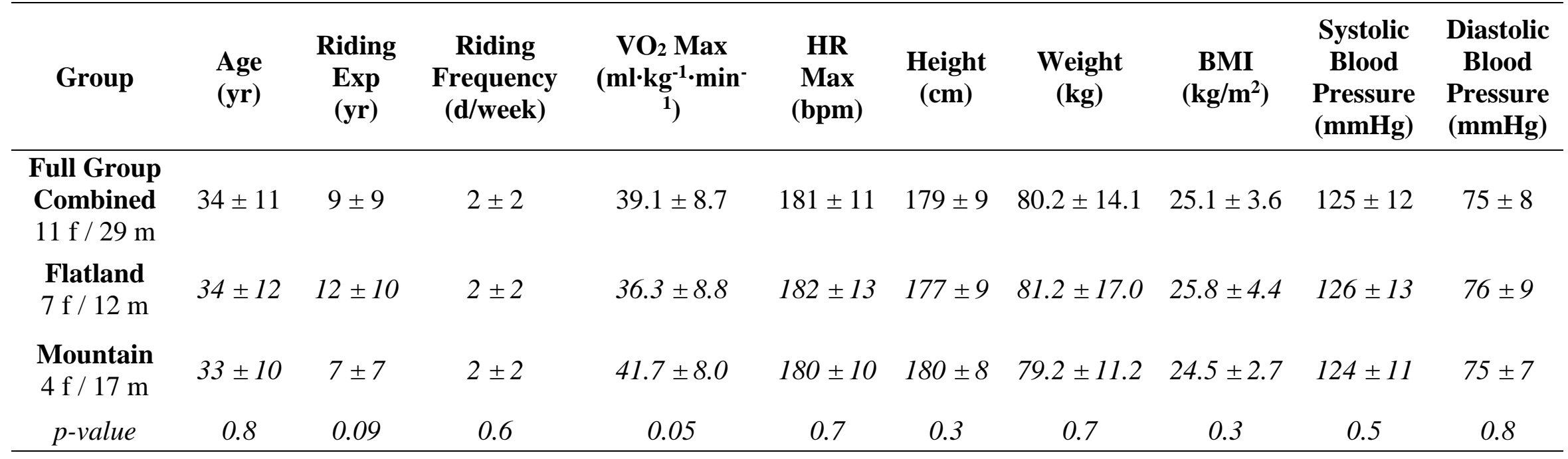

yr; year. d/week; days per week. bpm; beats per min. 
Mean riding speed across locations was $25 \pm 7 \mathrm{~km} / \mathrm{h}$ with an average top speed of $76 \pm 22$ $\mathrm{km} / \mathrm{h}$. Riders did not differ in their top speed across terrain types ( FL $70 \pm 23 \mathrm{~km} / \mathrm{h}$ vs. MN $80 \pm 21$ $\mathrm{km} / \mathrm{h}, \mathrm{p}>0.1$ ); however, MN riders rode at a faster average speed ( FL $22 \pm 5 \mathrm{vs}$. MN $27 \pm 8 \mathrm{~km} / \mathrm{h}$, $\mathrm{p}=0.05$ ). The number of turns completed during the representative course on average was $40 \pm 16$, which was significantly different between locations (FL 30 \pm 9 turns vs. MN 49 \pm 15 turns, $\mathrm{p}>0.001)$. 

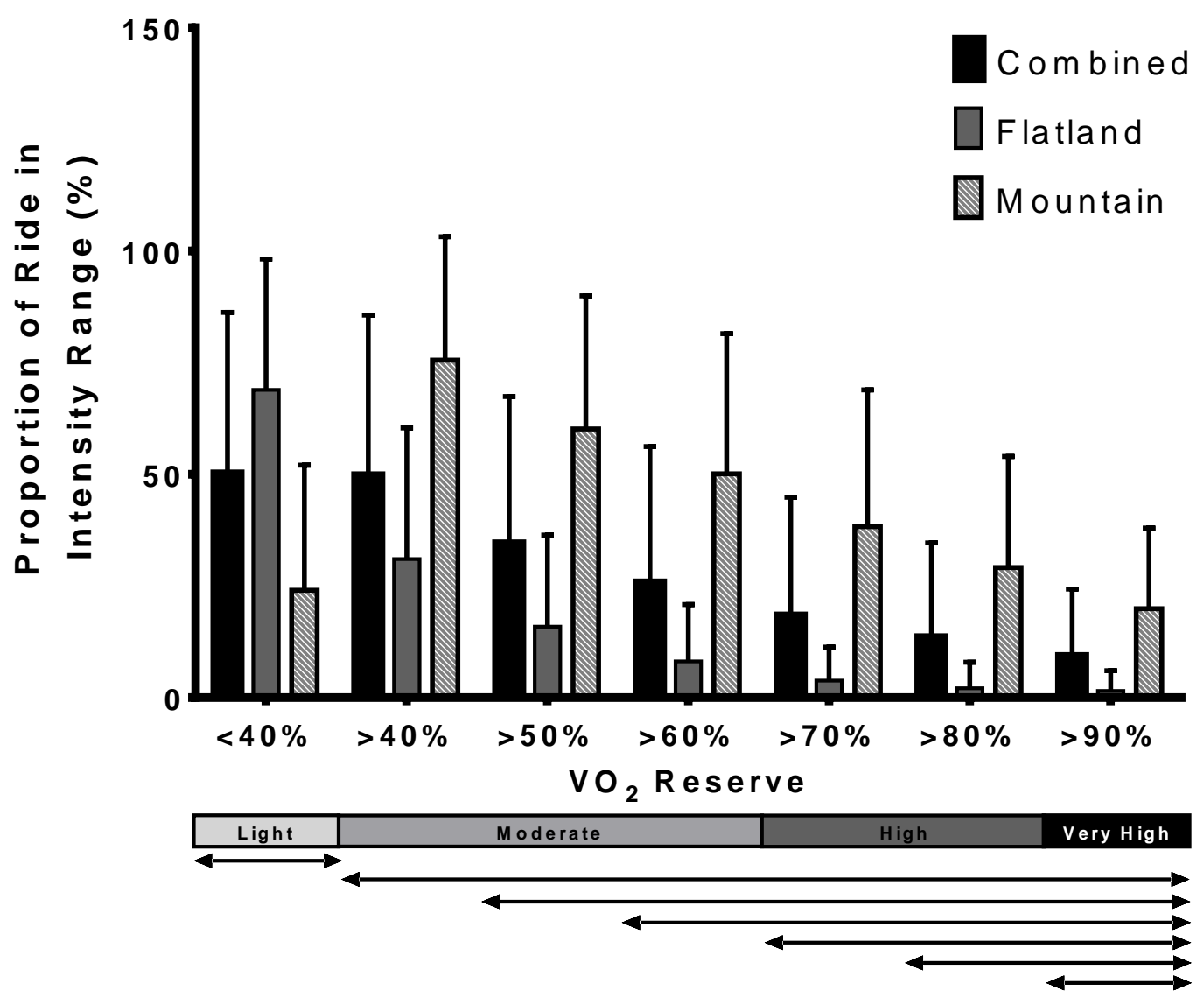

Figure 3. Cumulative percentage of a recreational ride spent in each intensity range $\left(\% \mathrm{VO}_{2} \mathrm{R}\right)$, starting below and above the minimum intensity for changes in health or fitness to occur $\left(40 \% \mathrm{VO}_{2} \mathrm{R}\right)$. (Note that, by design, the cumulative total of greater than and lesser than $40 \% \mathrm{VO}_{2} \mathrm{R}$ is equivalent to $100 \%$ ) The lower gradient bar demonstrates the intensity category based on ACSM classifications and the arrows below represent the intensities included in the cumulative deciles. Data expressed as means $\pm \mathrm{SD}$, *significant differences compared to $\mathrm{MN}$ at all intensities, $\mathbf{p}<0.05$. 
Metabolic Demand: The average metabolic demand of operating a snowmobile was $18.5 \pm 8.4 \mathrm{ml} \cdot \mathrm{kg}^{-1} \cdot \mathrm{min}^{-1}$ (or 5.4 \pm 2.4 METS) with considerable differences depending on the terrain type (Table 2). Average riding $\mathrm{VO}_{2}$ was generally lower in females than males $\left(13.9 \pm 4.2 \mathrm{ml} \cdot \mathrm{kg}^{-}\right.$ ${ }^{1} \cdot \mathrm{min}^{-1}$ vs. $\left.20.7 \pm 9.1 \mathrm{ml} \cdot \mathrm{kg}^{-1} \cdot \mathrm{min}^{-1}, \mathrm{p}=0.002\right)$. The small female sample size precluded more meaningful statistical analyses of this variable.

Table 2. Aerobic (VO2 max) and cardiovascular (HR) as measured during snowmobile riding compared by riding terrain. Data expressed as means \pm SD.

\begin{tabular}{|c|c|c|c|c|c|c|}
\hline Group & $\begin{array}{c}\text { Riding Time } \\
\text { (min) }\end{array}$ & $\begin{array}{c}\text { Average } \\
\text { Riding VO } \\
\left(\mathrm{ml}^{\circ} \mathrm{kg}^{-1} \cdot \mathrm{min}^{-1}\right)\end{array}$ & METs & $\begin{array}{c}\text { Average } \\
\text { Riding HR } \\
\text { (bpm) }\end{array}$ & $\begin{array}{c}\mathrm{VO}_{2} \mathrm{Max} \\
(\%)\end{array}$ & $\begin{array}{c}\text { HR Max } \\
(\%)\end{array}$ \\
\hline $\begin{array}{c}\text { Full Group } \\
\text { Combined }\end{array}$ & $21.3 \pm 8$ & $18.5 \pm 8.4$ & $5.4 \pm 2.4$ & $134 \pm 26$ & $50 \pm 22$ & $75 \pm 13$ \\
\hline Flatland & $17.6 \pm 4.3$ & $13.4 \pm 5.2$ & $3.8 \pm 1.5$ & $122 \pm 24$ & $38 \pm 14$ & $69 \pm 13$ \\
\hline Mountain & $24.6 \pm 9.1$ & $25.7 \pm 6.6$ & $7.8 \pm 1.2$ & $146 \pm 22$ & $67 \pm 20$ & $82 \pm 8$ \\
\hline$p$-value & -- & $<0.001$ & $<0.001$ & 0.004 & $<0.001$ & 0.01 \\
\hline
\end{tabular}

bpm; beats per minute. METs; metabolic equivalents.

The expected $\mathrm{HR}$ at the average riding $\mathrm{VO}_{2}$ was forecast to be $127 \pm 35 \mathrm{bpm}$, while the actual riding HR was measured at $132 \pm 24 \mathrm{bpm}$. The difference between the forecast HR and measured HR demonstrates an average HR inflation of $6 \pm 16 \mathrm{bpm}$ (Figure 4 ). A strong negative correlation was found between the size of the HR difference (Forecast-Ride HR) and percent max riding $\mathrm{VO}_{2}(\mathrm{r}=-0.8, \mathrm{p}<0.001)$. 
A)

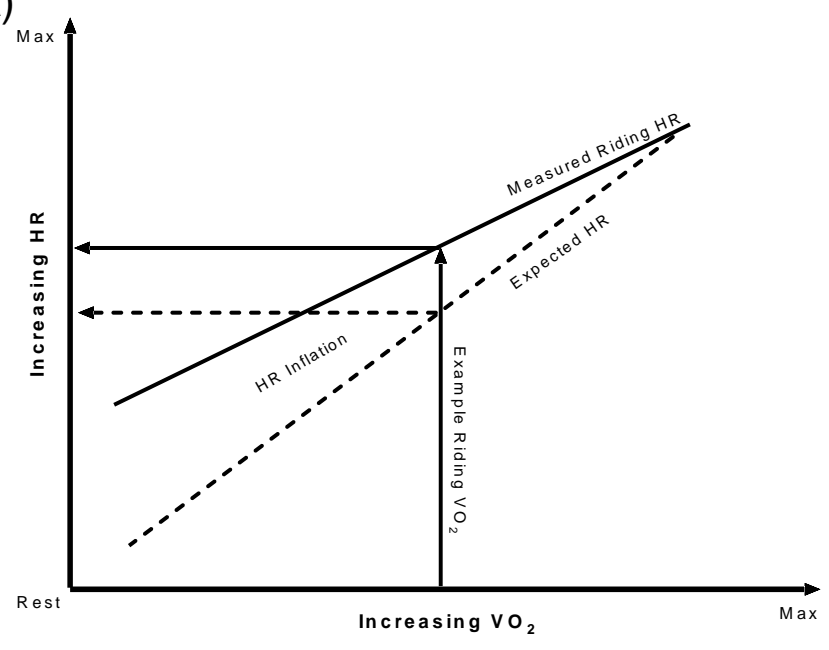

B)

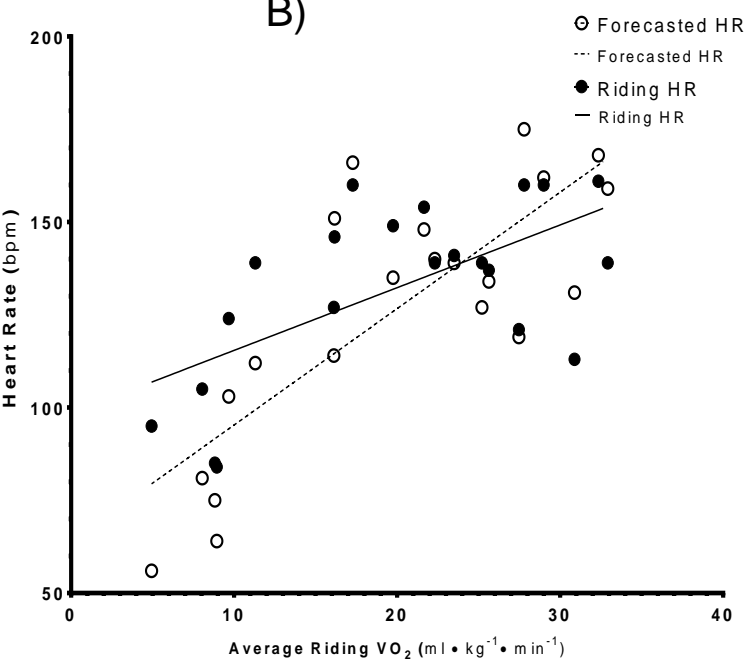

Figure 4. A) A theoretical representation of the calculation of $\mathrm{HR}$ inflation as the deviation from the linear relationship between heart rate (HR) and oxygen consumption $\left(\mathrm{VO}_{2}\right)$ as measured during the graded exercise test. Figure 4B) demonstrates actual individual rider data with the forecast and measured $\mathrm{HR}$ based on the mean riding $\mathrm{VO}_{2}$. This demonstrates the relationship of heart rate and $\mathrm{VO}_{2}$ during the graded exercise test compared with the "real-time" $\mathrm{HR}$ at an equivalent $\mathrm{VO}_{2}$ measured riding a snowmobile. With increasing intensity, $\mathrm{HR}$ inflation decreases as the rider progresses closer to maximal aerobic capacity, suggesting that HR monitoring may not be an appropriate measure of submaximal riding demand

Perceived Exertion: The easiest part of a ride (RPE min) was reported to be $8 \pm 1$, while RPE max was $15 \pm 2$ and RPE avg was $11 \pm 2$. RPE was similar across riding terrain for minimum (FL 7 $\pm 1, \mathrm{MN} 8 \pm 1$ ), maximum (FL 15 \pm 3 , MN 15 \pm 2 ), and average (FL 11 \pm 2 , MN 12 \pm 2 ) (all $\mathrm{p}>0.1)$. When comparing RPE by rider experience, there was no difference in how experienced riders ( $>5$ years; $n=20)$ perceived their ride compared to inexperienced riders $(\leq 5$ years; $n=15)$. Similarly, no associations existed between perceived effort and the rider's age, sex, overall fitness, riding speed, or aerobic intensity. A weak inverse association existed between the easiest parts of the ride (RPE min) and snowmobiling experience $(r=-0.4, p=0.046)$. 
Muscular Fatigue: Grip strength decreased $7 \pm 8 \%$ after the ride $(104 \pm 27 \mathrm{~kg}$ pre vs $97 \pm 25$ $\mathrm{kg}$ post, $\mathrm{p}<0.001)$. Fatigue differences between riding locations were not apparent when comparing the delta grip (FL $-6 \pm 6 \%$ vs. MN $-8 \pm 10 \%, \mathrm{p}=0.1$ ). Maximal vertical jump did not change significantly for the group as a whole $(4076 \pm 1057$ watts pre vs $4059 \pm 1076$ watts post, $\mathrm{p}=0.4$ ) and this was true for both riding terrains (FL $111 \pm 370 \mathrm{vs.} \mathrm{MN}-56 \pm 254 \mathrm{~W}, \mathrm{p}=0.06$ ). There was a weak negative correlation between the change in jump power and time spent standing during a ride $(\mathrm{r}=-0.3, \mathrm{p}=0.04)$.

Body position while riding: For an average rider, sitting time accounted for $41 \pm 38 \%$ of the ride and standing time accounted for $59 \pm 38 \%$ of the ride. There was an overall mean of $6 \pm 6$ transitions from sitting or standing positions, with MN riders transitioning slightly less between sitting or standing (FL $8 \pm 7$ vs. $\mathrm{MN} 4 \pm 5, \mathrm{p}=0.6$ ) as $\mathrm{MN}$ riders sat less and stood more than FL riders overall (standing: FL $27 \pm 23 \%$ vs. MN $90 \pm 17 \%$, p $<0.001$ ). Of the time spent standing $75 \pm 24 \%$ was while riding on bumpy terrain.

\section{Discussion}

\section{Metabolic Demand:}

The main novel finding of this study was that the metabolic demand of operating a snowmobile during a representative recreational ride was $18.5 \pm 8.4 \mathrm{ml} \cdot \mathrm{kg}^{-1} \cdot \mathrm{min}^{-1}$, or approximately 5.4 METS. The ACSM classifies activities as moderate intensity if they fall between an absolute metabolic demand of 3 to 6 METs ${ }^{33}$, thus supporting snowmobiling as a moderate intensity activity in this regard. Notably, snowmobiling has been previously underestimated in the Compendium of Physical Activity, which rates the demand of snowmobiling at 3.5 METs ${ }^{27}$. Inspection of the relative demand, accounting for baseline fitness, reveals that while half of a ride falls within a moderate intensity zone expected to stimulate alterations in health and fitness (i.e. $>40 \% \mathrm{VO}_{2} \mathrm{R}$ ), there are occasional excursions into higher 
intensities $\left(>60 \% \mathrm{VO}_{2} \mathrm{R}\right)\left(\right.$ Fig.3). The $\mathrm{ACSM}^{7}, \mathrm{CSEP}^{8}$, and $\mathrm{WHO}^{9}$ recommend that adults engage in at least 150 minutes of moderate intensity physical activity per week to maintain a healthy lifestyle. Snowmobiling could, thus, be considered part of a healthy aerobic routine provided that the rider is engaging in the activity at a moderate level for a portion of the time ${ }^{33}$.

An important secondary finding of this study is that there were differences in the demand of riding when comparing between $\mathrm{MN}$ and FL courses. $\mathrm{MN}$ riders spent a greater cumulative proportion of their ride above $40 \% \mathrm{VO}_{2} \mathrm{R}$, meaning that $\mathrm{MN}$ riders were engaging at a higher intensity (in the zone of expected health benefits) for a larger percentage of the total ride, irrespective of fitness. The greater aerobic demand of $\mathrm{MN}$ riding is responsible for driving up the mean data of both FL and MN riding combined as this represents a more extreme form of participation. When comparing across the two testing locations, participants did not differ in anthropometrics or riding characteristics, and riding intensities were normalized to fitness, thus any differences can be attributed to the terrain, machine and course characteristics.

A commonly used method for assessing PA intensity is to track HR; however, comparison of the regressions developed from the graded exercise test and snowmobile ride reveal that riding HRs were significantly inflated and thus heart rate is an inaccurate method of estimating intensity. This phenomenon was observed in other physical activities, that rely largely on grip and isometric forearm contractions, such as rock climbing ${ }^{81}$ and off-road vehicle riding $32,34,82$, which may also relate to the increased secretion of hormones, and psycho-emotional stress, as has been demonstrated in other motorsports ${ }^{82}$. During handgrip dominant sports, a disproportionate increase in $\mathrm{HR}$ occurs when matched for $\mathrm{VO}_{2}$ and is attributed to the increase in mean arterial pressure and total peripheral resistance in the arterioles of the forearm during intense small muscle (isometric) contractions, which induces a faster heartbeat to overcome the pressure ${ }^{83}$. HR inflation did not occur in all riders, particularly those who were working at a higher percentage of their $\mathrm{VO}_{2} \max$ (typically $\mathrm{MN}$ riders). This is logical, because $\mathrm{MN}$ riding 
involved more whole-body physical activity, thus the cardiovascular system was appropriately pushed closer to its ceiling. This was supported by the strong negative correlation between HR inflation and $\mathrm{VO}_{2}$ intensity.

\section{Muscular Fatigue:}

Snowmobiling was shown to elicit upper body muscular fatigue, similar to handlebar gripping in other OHV activities ${ }^{32,34}$ and thus demonstrating the requirement of upper body work during a typical ride. Konttinen et al. (2008) observed increased forearm flexor activation via electromyography during submaximal riding in recreational and competitive motocross-riders. This increased activation likely leads to grip fatigue post-ride that explains the observed decrease in grip strength. It is now well accepted that handgrip exercise can lead to acute and chronic alterations in vascular tone and blood pressure ${ }^{35}$, and thus this finding could have important health implications.

Fatigue was not noted in the lower body, potentially indicating that snowmobiling does not require substantial lower body involvement, or that the shortened representative ride was insufficient to induce fatigue in habituated riders. The weak correlation of standing time and reduced leg power suggests that the latter may have been the case, and that further exposure may have altered this effect. Congruently, those who sat for longer showed lower decrements in power. There were clear differences in standing time between riding locations such that MN riders were more active than FL riders and MN riders were transitioning significantly less, suggesting that MN riders were engaging their leg musculature more often.

\section{Body position while riding:}

For more than half of the total riding time, riders were in a standing posture, which represents a considerable portion of the ride and thus the common perception that snowmobile 
riding is a passive, seated activity should be challenged. In fact, riders often transitioned from sitting to standing positions. MN snowmobiles are designed to be lighter and less stable, so riders can make sharp turns by leaning their bodyweight into a turn, especially in deep "powder" snow. On FL this shifting of weight is not as critical, and riders can stay seated and steer the machine primarily with their arms for greater periods of time. This difference in riding style could contribute to the increased riding intensity observed in MN riders, who were thus using a greater proportion of a large muscle mass. This also suggests that riding, could increase muscular strength and endurance in core and other postural muscles if participation is on a regular basis.

\section{Perceived Exertion:}

Few meaningful relationships existed between terrain type, riding style and rider characteristics regarding how they perceived the demand of the ride. However, there was a weak negative association between the years of experience and the riding RPE min, which suggests that as a rider becomes more experienced, he or she becomes more economical as they develop better technical skills and more efficient riding styles. While the finding of no difference in RPE between MN and FL seems to suggest that riders did not perceive differences in riding difficulty between the two types of terrain, this could likely be affected by the rider's familiarity with the testing terrain as riders were recruited from local riding clubs. It would be expected that if riders had completed representative rides in both locations that the within-rider ratings would be dissimilar and more closely aligned with objective measures of physical demand.

\section{Manuscript Summary}

Snowmobiling is a recreational activity that demonstrates the potential to contribute meaningfully to the accumulation of total physical activity time. Snowmobiling is likely to be associated with similar health benefits to more common activities with the same moderate intensity cardiovascular fitness and muscular strength demands. Furthermore, the significant 
differences between riding terrain suggests that $\mathrm{MN}$ riding is significantly more physically demanding, and riders can accumulate a greater proportion of time at higher exercise intensities. This increased metabolic demand may confer additional benefits. This study has provided evidence, via the quantification of the activity-specific physiological demands, from which exercise-mediated health benefits can be interpreted based on previous literature. The data suggests that snowmobile riding should be considered a viable alternative form of PA that could benefit health and fitness when performed at a sufficient frequency, intensity and duration- thus providing relevance during winter periods when individuals are less active. 


\section{Chapter 4: Extended Methods and Additional Data Set}

\subsection{Methods}

Detailed methods of the primary measures used in this study are contained in the embedded manuscript (Chapter 4). In addition to these methods, supporting measures were taken before and after the discrete study, for which the methods are presented (or expanded upon) here.

The manuscript and additional data are presented separately, due to sampling challenges that resulted in unusable Backcountry metabolic data. As such, this portion of the dataset was removed from that which was prepared for peer-reviewed publication. Backcountry metabolic interpretation is excluded from this thesis; however, riding characteristics, muscular fatigue, and cardiovascular variables were still analyzed as described below, with results and following discussion presented after the manuscript.

\subsubsection{Survey}

A crucial first step of quantifying the demands of snowmobile riding was to define what represents the "normal" ride, and as a component of this, the prominent physical tasks associated with the sport. This was of critical importance to ensure that the demands measured in a representative ride are indeed reflective of the sport in a real-world setting. To define the average ride, habitual snowmobile riders (i.e. subject matter experts) were consulted to describe the sport in terms of their perceptions, overall experience and the rate at which specific tasks occurred.

Information gathering surveys were circulated to habitual and experienced snowmobilers via The Canadian Council of Snowmobile Organization's established connections with interest groups and clubs. This survey inquired about basic demographics, years of experience, and perceptions of riding. It also inquired about the physical tasks and terrain features associated with 
normal riding, the frequency at which those tasks/features occur, the intensity and total time. The survey comprised of roughly 35 questions using multiple choice, scales and dropdown menus to eliminate bias through open-ended questions, which allows participants to respond in a nonuniform manner, making data collection/interpretation more difficult.

This information was used to design a representative test-ride, which embodied the most important physical components/challenges regarding to the frequency, intensity and duration of their occurrence. Then, using appropriate scientific equipment, we collected data to quantify the acute demands of snowmobiling while participants undertook the activity in this controlled setting. It was anticipated that the sub-components of the physical tasks that collectively makeup snowmobiling will be varied, which will affect the physical demands of the activity.

A particular task of interest was digging out as there is existing literature on snow shoveling that demonstrates that it is physically demanding and could significantly contribute to the overall demand of snowmobiling if it occurred during a ride (Figure 5). During a snowmobile ride, a major cause of a snowmobile getting stuck is if the vehicle track spins in place and digs itself deeper into snow, or if a snowmobile gets caught on an immovable object (e.g. tree trunk) into a tree or snowbank. Staying on top of the snow can be aided by maintaining good speed and momentum, which at times can be difficult. As such, a snowmobile rider is more likely to get stuck if they are riding in deep snow and challenging terrain that requires them to slow down, thus requiring the rider to dig out their snowmobile. The survey also inquired about backpack wearing habits as riders participating in phase 2 of data collection, would be asked to wear a portable metabolic analyzer. This analyzer is attached to a mount that is strapped to the rider's back, which would make it similar, but lighter than a backpack full of gear. 


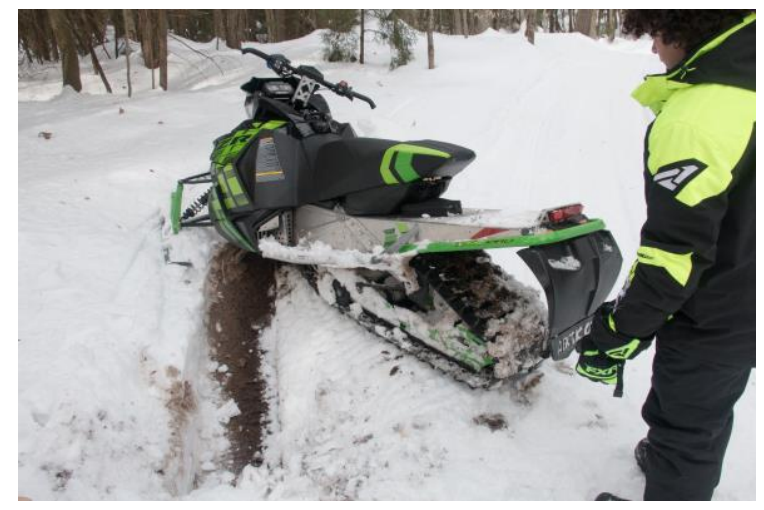

Figure 5. Photograph illustrating a lodged snowmobile that required digging out. The snowmobile had remained stationary while the track was rotating, thus digging itself beneath the surface of the snow and revealing the dirt underneath. This snowmobile was dislodged by digging and lifting the back end of the snowmobile to the side.

The second phase of data collection involved creating a representative ride based on survey results that condensed the tasks, features, and exposures of a multi-hour ride into approximately 20 minutes of riding. This time reduction maximized the number of subjects that could participate and reduced the commitment on the part of each participant as well as the level of discomfort associated with riding while wearing the metabolic monitoring equipment. For each location, recreational snowmobile riders were recruited from local snowmobile clubs. Riders provided their own riding gear, while helmets were provided to accommodate the mouth piece used for metabolic data collection. Each participant was led through a familiarization ride and was approved fit for riding by on-site snowmobiling safety experts. Snowmobile riders were asked to ride in a way that was reflective of their regular participation.

Prior to the representative ride, riders were asked to perform a maximal grip strength test and a maximal vertical jump test, which was used as a baseline to later determine upper and lower body muscular fatigue. An ActivPAL ${ }^{\mathrm{TM}}$ (PAL Technologies Ltd., Glasgow, UK) device (tri-axial inclinometer and accelerometer) was attached to the rider's thigh and used to determine the participant's postural adjustments throughout the ride. While riding, a portable metabolic 
system (Cosmed, K5; Rome, Italy) was used to quantify the cardiorespiratory demand and a GPS watch/altimeter with concomitant HR monitoring was worn to determine altitude, speed and HR. After the ride, riders immediately repeated the muscular fatigue tests and were asked to quantify the perceived exertion of the ride using the Borg 6-20 Rating of Perceived Exertion (RPE) ${ }^{76}$. This method of determining physical exertion has previously been used for monitoring PA that involves intermittent intensity changes, comparing session RPE to measured HR during activity was highly correlated, which suggests that session RPE is a valid method of monitoring exertion ${ }^{84}$. After a period of recovery, $\mathrm{VO}_{2}$ max was quantified using an electro-magnetically braked cycle ergometer (Racermate, Velotron; Seattle, Wa) and a linearly ramped protocol of increasing (1W every 2-8 seconds; starting at either 75 or 100 watts, depending on cycling familiarity and typical PA levels). Expired gas was measured using a laboratory grade analyzer (Cosmed, Quark; Rome, Italy).
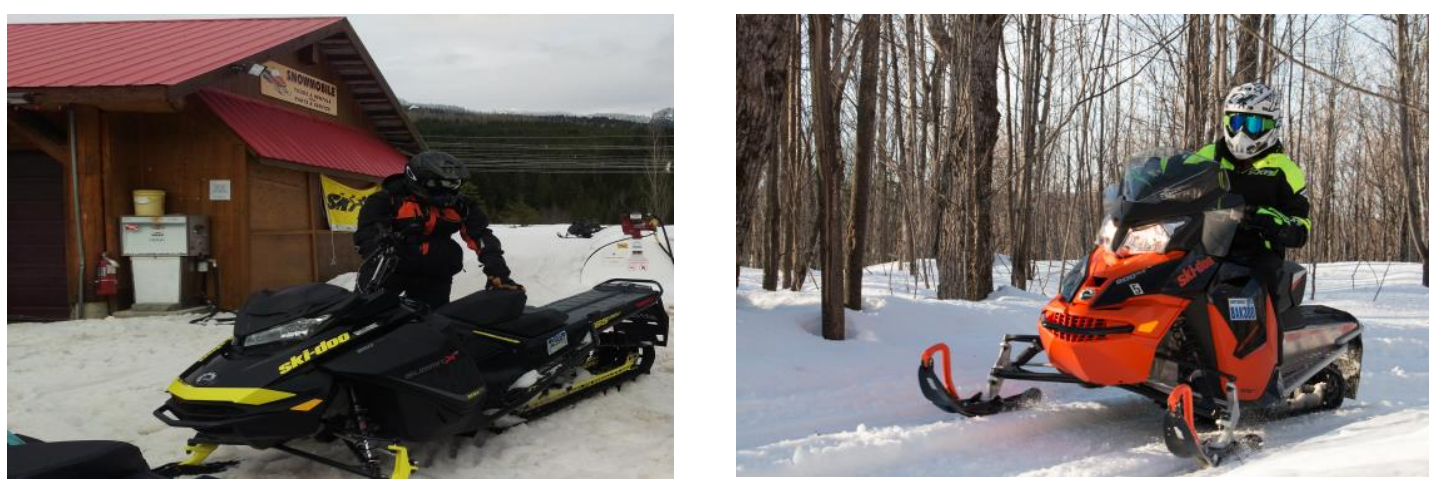

Figure 6. The photos above illustrate the two mains types of snowmobiles. Mountain snowmobiles (left) are typically designed for flotation in deep snow, therefore the body of the snowmobile is lighter, the skis are wider, and the back track is longer. This type of snowmobile is also less stable, to allow for turning in deep snow. Flatland snowmobiles are meant for trail riding only and can afford to be more robust thus the body is heavier, with shorter tracks and narrower skis. 


\subsubsection{Cardiovascular Demand}

A subset of riders (FL, $n=6$; BCR, $n=5$ ) were outfit with an impedance cardiography unit (Physioflow Enduro $^{\mathrm{TM}}$, Manatec Biomedical; Petit Ebersviller, France), which is a holster device that measures thoracic impedance via electrodes. Surface electrodes were used to detect impedance changes of blood flow through the thorax, as well as a single (lead 2) electrocardiogram, for gating to the cardiac cycle (See Figure 7). From these measurements stroke volume (SV), heart rate (HR), cardiac output (Q) and cardiac time intervals (e.g. ejection time) can be calculated. Exercising hemodynamics were further analyzed by comparing the cardiovascular response to the GXT and riding, matching for HR. To eliminate artifact, an abrading gel was used to prepare the skin, which allows a better signal to be measured. All electrodes and wiring were taped directly to the skin using medical-grade tape to reduce the possibility of shifting during the representative ride. The holster of the PhysioFlow device was fastened to the waist and all participants wore their base layer over top of the device to further ensure that the device and electrodes remain in place.

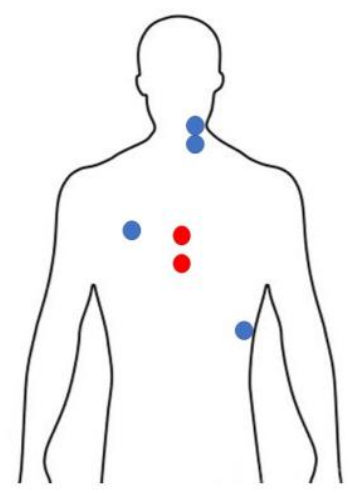

Figure 7. Electrode Placement for impedance cardiography. Surface electrodes are placed on the skin at the base of the neck (blue), underneath the right clavicle on the chest (blue), at the level of the diaphragm on the back (red) and on the left ribcage (blue). 


\subsubsection{Riding Location}

Following the primary investigation (see Chapter 3), an additional post-hoc data collection took place to represent an emerging trend in snowmobiling known as backcountry riding (BCR;) to be compared to mountain $(\mathrm{MN})$ and flatland $(\mathrm{FL})$ riding. $\mathrm{BCR}$ riding involves the navigation of deeper powder and the narrower "single track" trails while riding. This particular type of riding involves significantly less hill climbing than its MN counterpart, but because trails are narrower and less direct, there is a greater emphasis on turning. This increased number and severity of turns leads to slower average speeds due to the more technical trails compared to the other riding terrains. A majority of BCR riding is done on non-groomed terrain and this differs vastly from the compacted snow highways of the FL trails. This unique combination of factors merited additional data collection for BCR riding as it was identified by the snowmobile experts as an emerging area that was gaining popularity, but which was not captured by the initial survey data.

This testing took place in Maniwaki, Quebec with an ambient temperature of $-2.8 \pm 1.0{ }^{\circ} \mathrm{C}$ (range $=-7.1^{\circ} \mathrm{C}$ to $0.9^{\circ} \mathrm{C}$ ). The average ride was $21.7 \pm 5.6 \mathrm{~min}$, thus making it comparable to the other two locations. The mean altitude was $175 \pm 10 \mathrm{~m}$, the minimum altitude was $153 \pm 8 \mathrm{~m}$ and the maximum altitude was $196 \pm 22 \mathrm{~m}$ of the Maniwaki course, all of which was significantly different than the other terrain locations (all $\mathrm{p}<0.001$; Figure 8). All methods described above were followed unless otherwise stated, with the exception of additional statistical analyses as reported below. 

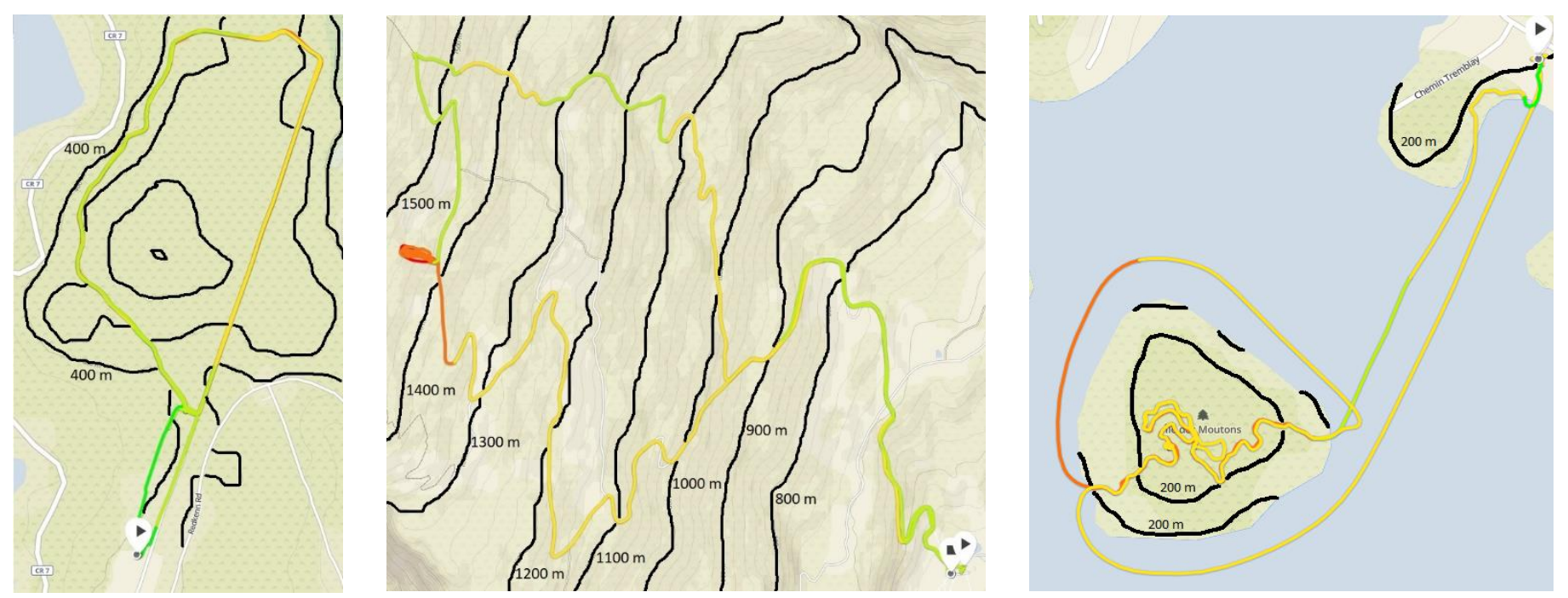

Figure 8. Topographical map of the composed rides across both locations with flatland (left), mountain (middle), and backcountry (right). The colours of the trail correspond to the level of intensity as measured by $H R$ response, thus green represents low intensity, yellow and orange is moderate intensity and red is high intensity.

\subsubsection{Statistical Analyses}

For the data analyzed in the manuscript (Chapter 3), participant characteristics and characteristics of the representative rides were compared across terrains using independent $t$ tests. Perceptual and physiological responses were also analyzed in this manner. To determine if snowmobiling elicited significant fatigue, paired t-tests were used to compare post strength and power tests from baseline. Pearson correlations were used to determine relationships between HR inflation and riding intensity $\left(\% \mathrm{VO}_{2} \max \right)$, as well as relationships between perception of effort and age, experience, and speed.

For the additional data set (results presented in Chapter 5), baseline participant and riding characteristics were compared via a 1 × 3 factorial ANOVA to determine whether differences 
existed between riders, or the way each rider engaged in snowmobiling based on the three different riding terrains. Post-hoc analysis was done using a Bonferroni correction factor. Paired t-tests were used to compare the forecast outcome of the linear regression with the measured riding response in the cardiovascular PhysioFlow data. These comparisons were used to determine if the inflation or a reciprocal deflation was apparent in the other cardiovascular measures. Pearson correlations were run between cardiovascular measures (HR, SV, Q, VET, EDFR, EDV, EF) and subject characteristics (age, gender, fitness), riding characteristics (maximum/average speed, number of turns) and muscular fatigue (percent delta grip or jump power) to determine if the cardiovascular system would respond differently based on varying levels of fatigue, speeds or individual characteristics. Statistical analyses were conducted using SPSS software (version 25; IBM, Chicago, IL, USA), with an a priori alpha of $\mathrm{P} \leq 0.05$. 


\section{Chapter 5: Additional Analyses}

\subsection{Phase 1: Survey Results}

\subsubsection{Respondent Characteristics}

The survey was distributed in Canada and the United States to define the average experience of a snowmobile rider. Over 4,015 responses were received, and the average was respondent was $49 \pm 13$ years old with $22.5 \pm 15.5$ years of experience and reporting participation in the activity $2 \pm 1$ times per week with the majority of respondents reported that a typical ride lasted 6 hours (14\% of survey responses). Respondents reported that they snowmobile for $26 \pm 23$ days of the season and travel $>4920 \mathrm{~km}$ over a season, or an average of $421 \mathrm{~km}$ each ride/day. The activity is typically performed in groups with friends (58\%), each rider in the group is riding 1-up (90\%), and a typical ride spans over a single day (76\%) of riding. The majority of riders perceived the activity of snowmobiling to be neither easy nor difficult (extremely easy 5.2\%, moderately easy $14.5 \%$, slightly easy $8.3 \%$, neither easy nor difficult $29 \%$, slightly difficult $27.6 \%$, moderately difficult $14.5 \%$, extremely difficult $0.9 \%$ ).

\subsubsection{Physical Tasks}

Survey respondents quantified the demands associated with a ride and the frequency at which they occur. A majority of respondents (60\%) reported riding hilly terrain most often. On average in a typical ride, $56 \pm 39 \%$ of the time was spent on flat trails and $46 \pm 39 \%$ on undulating ground. Time spent on trails was $83 \pm 24 \%$ of a typical ride versus $17 \pm 24 \%$ being spent in the back country. Snowfall and trail maintenance could also play into the physical demands; thus, riding on groomed trails was quantified as $67 \pm 23 \%$ of ride time, and riding on non-groomed terrain was $33 \pm 23 \%$ of total ride time. Another factor investigated was sitting versus standing 
time during an average ride. It was reported that $79 \pm 22 \%$ of total ride time was spent sitting, and $21 \pm 22 \%$ time was spent standing.

After analyzing the survey to determine the ride composition, a divergence occurred in terrain features and riding habits based on the terrain that the respondent rode most often. To investigate the perceived physical demand across different terrains, the survey results were analyzed as a comparison between MN and FL riders (Figure 9). As would be expected, MN riders reported spending significantly less time on flat terrain, at $29 \pm 18 \%$ of riding time, versus $82 \pm 18 \%$ of the time for FL riders ( $<<0.001$ ). Considering riding time performed on undulating terrain $\mathrm{MN}$ riders reported spending $71 \pm 43 \%$ of a ride in these conditions, versus $31 \pm 27 \%$ of ride time for FL riders ( $<<0.001)$. MN riders reported groomed trail use $51 \pm 38 \%$ of the time, compared to FL riders who spend $81 \pm 19 \%$ of their ride on a trail $(\mathrm{p}<0.001)$. Finally, of the time spent on trails, $\mathrm{MN}$ riders were more likely to spend time on a trail that had not been recently groomed compared to FL riders ( $56 \pm 28 \% \mathrm{MN}, 70 \pm 22 \% \mathrm{FL} ; \mathrm{p}<0.001)$.
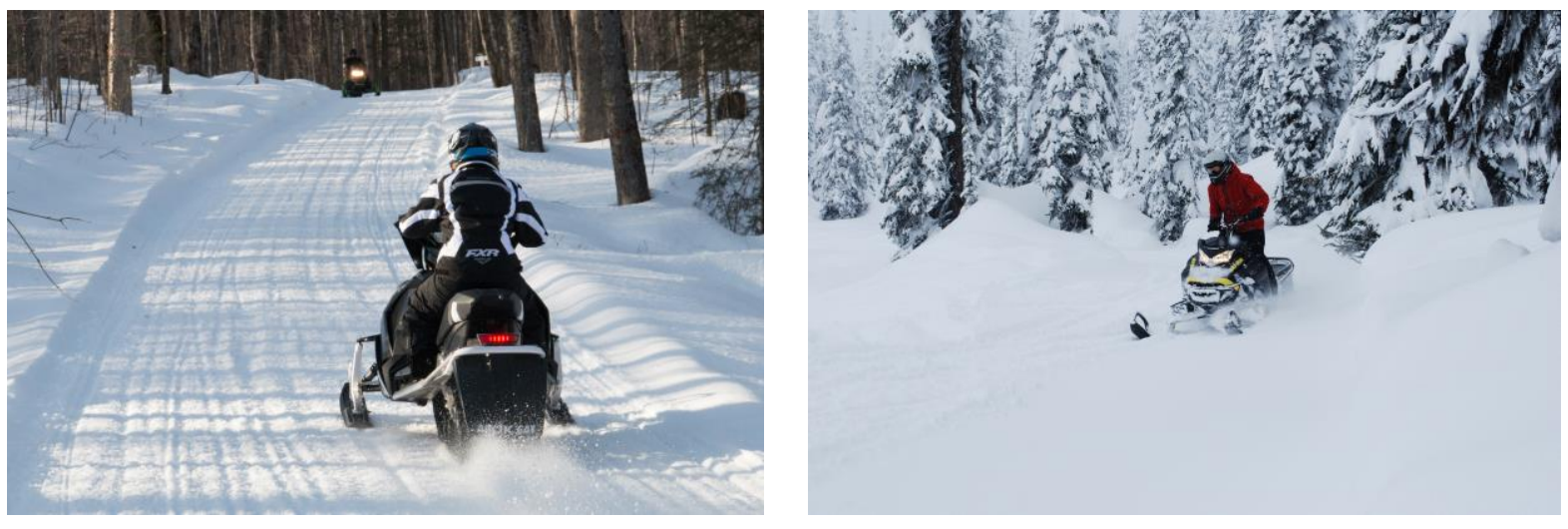

Figure 9. The photos above illustrate the difference between groomed (FL and MN) and nongroomed (BCR and MN) riding. Groomed trails (left) are snow compacted lanes that are usually wide enough to accommodate a single snowmobile if not two snowmobiles (generally 
split between two-way traffic). Non-groomed riding (right) takes place in untouched deep snow, where snow is only compacted if a rider retakes the line that they previously created. This type of riding involves dropping in between trees and riding around cut-blocks (open or forested fields of deep snow).

The survey also inquired about physically demanding tasks associated with snowmobile riding, beyond the actual ride itself, that commonly occur with participation. There was great variability in the responses given for quantifying the main task of 'digging out', a majority of respondents reported that this task did not occur on a typical ride (48\%) (Digging out occurs at least once $36 \%$, Twice $10 \%, 3$ times $3 \%$, 4 or more times per ride $3 \%$ ). The peripheral task of digging out a lodged snowmobile was reported as the most demanding task associated with snowmobiling. Half of all survey respondents reported that digging out generally takes 5-10 minutes, and its difficulty was rated at a $7 \pm 2$ out of 10 -point difficulty scale. Most MN riders reported digging out 4 or more times on a regular ride, while digging out at least once during a ride was the second most popular survey response. For FL riders, digging out does not always occur on a regular ride as reported by a majority $(60 \%)$ of respondents $(\mathrm{p}<0.001$ when compared to $\mathrm{MN}$ ). Irrespective of terrain, $40 \%$ of respondents reported that digging out took 5-10 min. There was no difference between how riders perceived the difficulty of the task as MN riders rated it at $7 \pm 2$ and FL riders rated it at $7 \pm 2$ on a 10 -point scale $(\mathrm{p}=.3)$. 


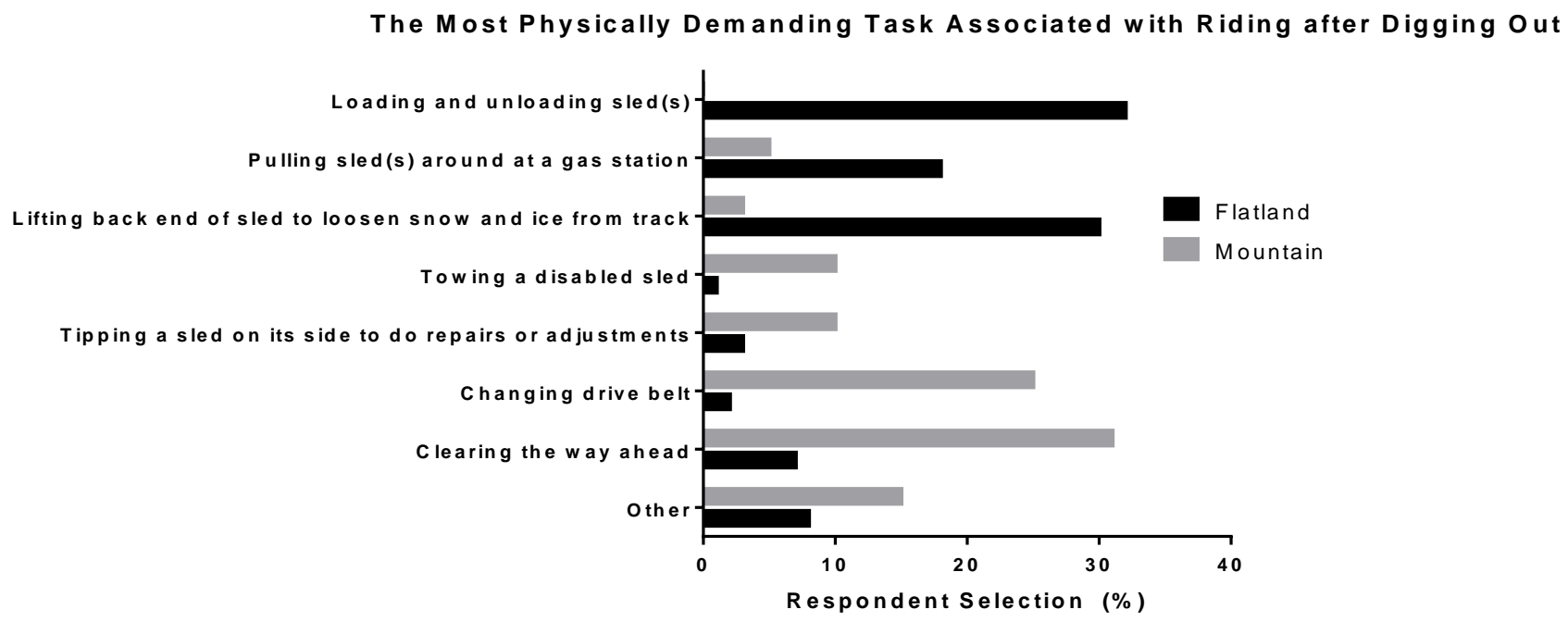

Figure 10. The survey inquired about which task was the second most demanding peripheral task after digging out, from the choices listed. The figures demonstrate the percentage of survey respondents who chose a particular task as being the second most physically demanding. An emerging trend of significant differences between riding terrains is apparent as the majority of MN riders who believe that changing the drive belt is the second most demanding task compared to FL riders who rank loading or unloading a snowmobile as the second most difficult task.

Aside from digging out, $\mathrm{MN}$ riders found that clearing the path ahead was the most difficult activity (30.8\%) (Figure 10). Clearing the path ahead is required when branches or fallen trees cover the path. For MN riders clearing the path ahead occurred 2-3 times on an average ride, took $<5$ minutes, and was rated at a $6 \pm 2$ on a 10 -point difficulty scale. For FL riders, loading and unloading snowmobile(s) from a truck or trailer was the second most difficult activity (27.9\%). Loading and unloading snowmobile(s) takes FL riders $<5$ minutes and was a $5 \pm 2$ out of 10 -point difficulty scale (all, $\mathrm{p}<0.001$ ). Respondents were asked about pack wearing habits as additional weight on the rider could increase physical demands, $69 \%$ of mountain riders carried additional gear compared to $58 \%$ of FL riders $(\mathrm{p}<0.001)$. Generally, the weight of packs 
carried was 10-20 additional $\mathrm{lb}$ for $\mathrm{MN}$ riders (48 \%) compared to FL riders who carried 0-10lb of gear $(50 \%)(\mathrm{p}<0.001)$. Standing time was also reported in this survey, which MN riders spent $49 \pm 34 \%$ of the time standing and FL riders spent $17 \pm 18 \%$ of their ride standing $(\mathrm{p}<0.001)$.

\subsection{Phase 2: Physical Demands Data Collection}

\subsubsection{Subject and Riding Characteristic}

The additional data set of BCR riders allowed for more meaningful gender and age-based comparisons by increasing the sample size. Across all groups, systolic blood pressure increased with age $(\mathrm{p}=0.004)$ and was generally higher in males $(\mathrm{p}=0.01)$. As expected, being younger and female related to having lower body mass and smaller body height (both, $\mathrm{p}<0.001$ ). Being over 40 years old and female was associated with a decreased aerobic fitness $(\mathrm{p}=0.004)$. Descriptive participant and riding characteristics for BCR riders are reported below in Table 3 and 4, respectively. 
Table 3. The anthropometric and resting cardiovascular characteristics of the BCR snowmobile riders who participated in testing. Snowmobiling frequency and years of experience of the riders are also reported. Data expressed as means \pm SD.

\begin{tabular}{|c|c|c|c|c|c|c|c|c|c|c|}
\hline Group & $\begin{array}{l}\text { Age } \\
(y r)\end{array}$ & $\begin{array}{c}\text { Riding } \\
\text { Exp. } \\
\text { (yr) }\end{array}$ & $\begin{array}{c}\text { Riding } \\
\text { Freq. } \\
\text { (d/week) }\end{array}$ & $\underset{\left(\mathrm{ml}^{\prime} \mathrm{kg}^{-1} \cdot \mathrm{min}^{-1}\right)}{\mathrm{MOx}_{2}}$ & $\begin{array}{c}\text { HR Max } \\
\text { (bpm) }\end{array}$ & $\begin{array}{c}\text { Height } \\
\text { (cm) }\end{array}$ & $\begin{array}{c}\text { Weight } \\
\text { (kg) }\end{array}$ & $\begin{array}{c}\text { BMI } \\
\left(\mathrm{kg} / \mathbf{m}^{2}\right)\end{array}$ & $\begin{array}{l}\text { Systolic } \\
\text { Blood } \\
\text { Pressure } \\
(\mathrm{mmHg})\end{array}$ & $\begin{array}{l}\text { Diastolic } \\
\text { Blood } \\
\text { Pressure } \\
(\mathrm{mmHg})\end{array}$ \\
\hline $\begin{array}{l}\text { Flatland } \\
7 \mathrm{f} / 12 \mathrm{~m}\end{array}$ & $34 \pm 12$ & $12 \pm 10$ & $2 \pm 2$ & $36.3 \pm 8.8$ & $182 \pm 13$ & $177 \pm 9$ & $81.2 \pm 17.0$ & $25.8 \pm 4.4$ & $126 \pm 13$ & $76 \pm 9$ \\
\hline $\begin{array}{l}\text { Mountain } \\
4 \mathrm{f} / 17 \mathrm{~m}\end{array}$ & $33 \pm 10$ & $7 \pm 7$ & $2 \pm 2$ & $41.7 \pm 8.0$ & $180 \pm 10$ & $180 \pm 8$ & $79.2 \pm 11.2$ & $24.5 \pm 2.7 *$ & $124 \pm 11$ & $75 \pm 7$ \\
\hline $\begin{array}{c}\text { Backcountry } \\
7 \mathrm{f} / 13 \mathrm{~m}\end{array}$ & $36 \pm 11$ & $11 \pm 12$ & $1 \pm 1$ & $34.6 \pm 11.5$ & $173 \pm 9$ & $174 \pm 7$ & $83.7 \pm 17.1$ & $26.9 \pm 4.6$ & $125 \pm 11$ & $81 \pm 8$ \\
\hline p-value & 0.8 & 0.3 & 0.2 & 0.06 & & 0.08 & 0.6 & 0.05 & 0.8 & 0.06 \\
\hline
\end{tabular}

Exp; experience. Freq; frequency. yr; year. d/week; days per week. * Significantly different from BCR. 
Table 4. Ride characteristics of snowmobile riders who participated in testing at each geographic location. Data expressed as means \pm SD.

\begin{tabular}{|c|c|c|c|}
\hline Group & $\begin{array}{c}\text { Mean Riding speed } \\
(\mathbf{k m} / \mathbf{h r})\end{array}$ & $\begin{array}{c}\text { Top Riding speed } \\
(\mathbf{k m} / \mathbf{h r})\end{array}$ & Number of Turns \\
\hline Flatland & $22 \pm 5 *$ & $70 \pm 23$ & $30 \pm 9 *$ \\
\hline Mountain & $27 \pm 8 *$ & $80 \pm 21$ & $49 \pm 15^{\dagger}$ \\
\hline Backcountry & $13 \pm 5^{\dagger}$ & $72 \pm 21$ & $47 \pm 13^{\dagger}$ \\
\hline$p$-value & $<0.001$ & 0.3 & 0.001 \\
\hline
\end{tabular}

$\mathrm{km} / \mathrm{hr}$; kilometer per hour. * Significantly different from BCR, ${ }^{\dagger}$ Significantly different from FL.

\subsubsection{Cardiovascular Demand}

The mean riding HR was $123 \pm 25$ bpm for BCR riders, which was similar to FL riders and significantly lower than $\mathrm{MN}$ riders (122 $\pm 24 \mathrm{bpm}, 146 \pm 22 \mathrm{bpm}, \mathrm{p}=0.005)$. BCR riders were working at $71 \pm 12 \%$ of maximum HR, but only MN riders were working at a significantly higher percentage of maximum HR than FL riders (FL 69 \pm 13 , MN 82 $\pm 8, \mathrm{p}=0.03$ ). The mean riding cardiovascular variables (HR, SV, Q, VET, EDFR, EDV, EF) as measured using impedance cardiography (PhysioFlow, Enduro) in a small subset of riders is reported below comparing by location (Table 5) and exercise modality (Table 6). There was a moderate inverse relationship between the decrement in grip strength and average riding $\mathrm{HR}(\mathrm{r}=-0.6, \mathrm{p}=0.05)$ and $\mathrm{Q}(\mathrm{r}=-0.7$, $\mathrm{p}=0.03)$. 
Table 5. The mean riding cardiovascular variables as measured over the course of the ride, using impedance cardiography in a subset of FL and BCR riders. Data expressed as means \pm SD.

\begin{tabular}{ccccccccc}
\hline Group & $\begin{array}{c}\text { HR } \\
(\mathbf{b p m})\end{array}$ & $\begin{array}{c}\text { SV } \\
(\mathbf{m L})\end{array}$ & $\begin{array}{c}\mathbf{Q} \\
(\mathbf{L} / \mathbf{m i n})\end{array}$ & $\begin{array}{c}\text { VET } \\
(\mathbf{m s})\end{array}$ & EDFR & $\begin{array}{c}\text { EDV } \\
(\mathbf{m L})\end{array}$ & $\begin{array}{c}\text { EF } \\
(\boldsymbol{\%})\end{array}$ & $\begin{array}{c}\text { Signal Quality } \\
(\boldsymbol{\%})\end{array}$ \\
\hline Combined & $139 \pm 18$ & $95 \pm 24$ & $13.3 \pm 3.7$ & $249 \pm 26$ & $71 \pm 15$ & $139 \pm 40$ & $70 \pm 8$ & $86 \pm 13$ \\
$\begin{array}{c}\text { Flatland } \\
\mathrm{n}=6\end{array}$ & $142 \pm 10$ & $107 \pm 25$ & $15.2 \pm 3.7$ & $241 \pm 19$ & $72 \pm 13$ & $148 \pm 33$ & $72 \pm 3$ & $87 \pm 12$ \\
$\begin{array}{c}\text { Backcountry } \\
\text { n=5 }\end{array}$ & $135 \pm 25$ & $82 \pm 15$ & $11.0 \pm 2.1$ & $259 \pm 33$ & $71 \pm 19$ & $129 \pm 50$ & $67 \pm 12$ & $84 \pm 15$ \\
\begin{tabular}{c}
$p$-value \\
\hline
\end{tabular} & 0.6 & 0.08 & 0.05 & 0.3 & 1.0 & 0.5 & 0.3 & 0.7 \\
\hline
\end{tabular}

bpm; beats per minute. $\mathrm{mL}$; milliliter. $\mathrm{L} / \mathrm{min}$; litres per minute. $\mathrm{ms}$; milliseconds. 
Table 6. HR-matched impedance cardiography variables as measured during riding and during the GXT in a small subset of riders $(n=9 ; F L=6, B C R=5)$. Data expressed as means \pm SD.

\begin{tabular}{ccccccccc}
\hline Exercise Modality & $\begin{array}{c}\text { HR } \\
(\mathbf{b p m})\end{array}$ & $\begin{array}{c}\text { SV } \\
(\mathbf{m L})\end{array}$ & $\begin{array}{c}\mathbf{Q} \\
(\mathbf{L} / \mathbf{m i n})\end{array}$ & $\begin{array}{c}\text { VET } \\
(\mathbf{m s})\end{array}$ & EDFR & $\begin{array}{c}\text { EDV } \\
(\mathbf{m L})\end{array}$ & $\begin{array}{c}\text { EF } \\
(\%)\end{array}$ & $\begin{array}{c}\text { Signal } \\
\text { Quality } \\
(\%)\end{array}$ \\
\hline Graded Exercise Test & $142 \pm 19$ & $95 \pm 20$ & $13.5 \pm 3.3$ & $249 \pm 34$ & $62 \pm 16$ & $129 \pm 26$ & $73 \pm 7$ & $89 \pm 19$ \\
\multicolumn{1}{c}{ Riding } & $139 \pm 18$ & $95 \pm 25$ & $13.2 \pm 3.6$ & $247 \pm 29$ & $72 \pm 13$ & $138 \pm 41$ & $69 \pm 9$ & $85 \pm 14$ \\
\hline
\end{tabular}

bpm; beats per minute. $\mathrm{mL}$; milliliter. L/min; litres per minute. ms; milliseconds. 


\subsubsection{Muscular Strength \& Power}

For BCR riders, there was no significant change in induced grip strength (pre $102 \pm 28 \mathrm{~kg}$ vs. post $100 \pm 29 \mathrm{~kg}, \mathrm{p}=0.3)$. BCR riders fatigued significantly less than $\mathrm{MN}$ riders $(\mathrm{MN}-8 \pm 10 \%$, $\mathrm{p}=0.04$ ). Total maximal vertical jump did not differ pre to post (pre $4061 \pm 1018$ watts vs. post $4131 \pm 1045$ watts, $\mathrm{p}=0.1$ ). Similarly, BCR riders did not differ from the other riders in the delta jump power (BCR 100 \pm 196 watts; FL 111 \pm 370 watts, $p=1.0 ; \mathrm{MN}-56 \pm 254$ watts, $\mathrm{p}=0.3$ ). The weak negative correlation between the change in jump power and standing time did not change with the addition of $\mathrm{BCR}$ data $(\mathrm{r}=-0.3, \mathrm{p}=0.04)$, and neither did the positive weak correlation with sitting time and the change in jump power $(r=0.3, p=0.04)$.

\subsubsection{Body Position while Riding}

Standing accounted for $40 \pm 31 \%$ of total ride time in the BCR test, which was significantly different from MN riders but not FL riders (FL 27 $\pm 23 \% \mathrm{p}=0.3$; MN $90 \pm 17 \%$ $\mathrm{p}<0.001)$. Of the total ride time, $\mathrm{BCR}$ riders were on bumpy terrain for $27 \pm 25 \%$ of the total ride time, which was significantly less than MN riders (FL 22 $\pm 20, p=1.0 ; \mathrm{MN} 67 \pm 26, \mathrm{p}<0.001$ ). BCR riders transitioned $7 \pm 6$ times between sitting and standing, which was not different than either of the other riding locations ( $\mathrm{FL} 8 \pm 7, \mathrm{p}=1.0 ; \mathrm{MN} 4 \pm 5, \mathrm{p}=0.4$ ).

\subsubsection{Perceived Exertion}

$\mathrm{BCR}$ riders reported the minimum riding exertion ( $\mathrm{RPE}$ min) as $8 \pm 2$, the maximum exertion (RPE max) as 15 \pm 3 , and the average exertion as 12 \pm 2 (RPE avg). RPE was similar across riding terrain for minimum (FL 7 $\pm 1, \mathrm{MN} 8 \pm 1$ ), maximum (FL 15 $\pm 3, \mathrm{MN} 15 \pm 2$ ), and average (FL 11 $\pm 2, \mathrm{MN} 12 \pm 2$ ) riding (all p $>0.1$ ). No relationships were found between the rider's perceived effort and the rider's age, gender, overall fitness, riding experience, riding frequency, or riding speed. 


\section{Chapter 6: Discussion}

\subsection{Metabolic Demand}

The main finding of the current study was that the aerobic demand of operating a snowmobile during a representative recreational snowmobile ride was at or above $40 \% \mathrm{VO}_{2} \mathrm{R}$ (the point at which health benefits are expected to occur) for $50 \pm 36 \%$ of total ride time. The mean aerobic demand while riding was $18.5 \pm 8.4 \mathrm{ml} \cdot \mathrm{kg}^{-1} \cdot \mathrm{min}^{-1}$ (5.4 METs), which was approximately $50 \%$ of maximal capacity for the group studied. This suggests that snowmobiling should, thus, be classified as a moderate intensity physical activity according to the ACSM ${ }^{7}$. Other activities which share a similar physical intensity to snowmobile riding include; doubles tennis, lawn mowing, fast ballroom dancing, light effort cycling, and brisk walking at $4 \mathrm{mph}^{33}$. As such, it is reasonable to suggest that snowmobiling could likely contribute to the meaningful accumulation of activity time in the winter months, if the rider participates for a sufficient duration and frequency.

Increased activity time could also be accumulated through the other activities associated with snowmobiling, these tasks would increase the NEAT or caloric energy expenditure and thus the potential benefits that can be associated with increased activity ${ }^{26}$. From the survey responses, digging out is one of the primary tasks that occurs in conjunction with snowmobile riding, while others include lifting the rear end of a snowmobile or clearing the brush ahead. Lifting the rear end of a snowmobile would be required if the snowmobile was stuck, or if the track had become frozen with ice after being parked, while clearing the brush ahead would be required if branches, fallen trees, or other obstacles were blocking the path ahead. For MN riders, digging out appears to be much more commonly encountered and thus the demands of riding and the peripheral activities may be greater. Snow shoveling is estimated in the compendium of physical activities to range from 5.3-7.5 METs depending on intensity ${ }^{27}$, and thus an average individual would burn an additional 35-90 calories $\left(6-9 \mathrm{kCal} \cdot \mathrm{min}^{-1}\right)$ in the time it would take dig out their snowmobile each time is was stuck (calculations based on $70 \mathrm{~kg}$ person, approximated 5-10 minutes of digging) ${ }^{1}$. If this occurs 4 or more times in a typical ride, this would mean up to 120 $360 \mathrm{kCals}$ per ride. Other activities such as clearing brush or lifting the end of a snowmobile 
would likely require between 3.5-4.5 METs if you compare this task to the previously measured demands of standing/ lifting more than $50 \mathrm{lb}^{27}$, therefore that same $70 \mathrm{~kg}$ individual would burn an additional $4-5 \mathrm{kCal} \cdot \mathrm{min}^{-1}$ for those activities ${ }^{1}$. Snowmobile riders are also likely to be wearing a backpack with up to $10 \mathrm{lbs}$ of gear, which could potentially increase the physical demands, thus increasing caloric energy expenditure. In effect, snowmobiling is a moderate physical activity that involves other indirect increases in NEAT, which suggests that frequent participation have the potential to lead to positive changes in weight and health.

\subsection{Cardiovascular Demand}

HR inflation was a phenomenon observed in the current study, where an inflation of riding heart rate occurred at the same given metabolic demand compared to the measured GXT response. This confirms an effect that has previously been observed in other OHV research ${ }^{32}$. As previously stated, apart from the discussed physiological stress, motorized vehicle riding in natural environments also presents a significant psychological stress ${ }^{39-41}$, and the body responds to this stress by increasing sympathetic activation that increases HR ${ }^{49}$. The current study suggests that even recreational riding can increase sympathetic activation as noted by the HR inflation. This may have been caused because riders were constantly aware and responding to environmental cues like terrain features, this acknowledgment of risk is likely to induce psychological stress. In the representative course, there were a number of straightaways, single track, hills and gullies. Riders also had to be aware of oncoming or impeding traffic, fixed objects surrounding or on the trail, as well as being knowledgeable about the terrain itself to avoid cliff drops, thin ice or rocky surfaces. This means that while riding, individuals would have to be alert so that they could respond and adjust their speed or turning based on the terrain features. The cardiovascular response can also be altered by high ambient temperatures and humidity ${ }^{38}$, which results in a phenomenon known as cardiovascular drift . Cardiovascular drift is characterized by an increased $\mathrm{HR}$ to combat decreasing Q, SV, and plasma volume in response to exercise in hot environments ${ }^{85}$. During a snowmobile ride, riders are wearing various layers of clothing to retain body heat for protection from the cold. The combination of ineffective evaporation of sweat, inability to dissipate heat and the heat produced from exercise could 
increase the temperature of the rider's microenvironment. According to the impedance cardiography data, decreases in SV or EDV did not occur when riding compared to the GXT. This suggests that cardiovascular drift was likely not initiating major factor in increasing cardiovascular response, but specific measures of plasma volume were not tracked.

Contrary to increases in HR being driven by a reduction in plasma volume and a compensatory change in rate with decreasing SV, increases in SV have actually been noted in OHV riding. Sanna et al. (2017) noted increases in SV volume and attributed these differences to an increase in sympathetic activity or as a response to dynamic muscle contraction. Cardiac filling (pre-load) may have been augmented through the mechano-metabo reflex or due to the fact that the dynamic muscle contractions involved in motorcycle riding may have overpowered the isometric contractions (isometric exercise decreases SV) ${ }^{47}$. Comparatively, this is a normal response to exercise, the cardiovascular system incrementally increases SV by intrinsically enhancing diastolic cardiac filling followed by a stronger systolic contraction to meet the increasing aerobic demand ${ }^{1}$. A major limitation of that paper was that there was no comparison to exercise, thus it is difficult to discern whether this cardiovascular response is specific to OHV riding or if it is simply a normal response to incremental exercise.

Although underpowered for statistical comparison, current impedance cardiography data suggests that there may be a difference in the cardiac preload when comparing to exercise. Differences in SV and Q appear to be minimal when compared to exercise matched at the average riding HR. EDV while riding a snowmobile appears to be higher than that recorded at a matched HR while on a stationary bike and this is influenced by a higher EDFR, however the standard deviations mask any significance. These variables seem to suggest a greater preload.

The suggested cardiovascular response may be driven by the exercise pressor reflex, which modulates sympathetic tone based on peripheral reflex signals stemming from the contracting muscle's metabolic and mechanical conditions ${ }^{48}$. During snowmobiling riding, individuals must maintain their grip on the handlebars, requiring significantly tighter gripping when going over hills or with increasing speed. Riders must maintain a constant firm grip on the handlebars as it is the only means of holding onto the machine, likely leading to the eventual 
accumulation of post-contraction metabolites. Previous data has demonstrated that above a certain metabolite concentration, the exercise pressor reflex causes significant increases in blood pressure and sympathetic activity ${ }^{86}$. Since gripping is maintained by the forearms, it is likely that the small size of the contracting musculature enhances the response as the metabolite threshold would be more easily reached. This is supported by the moderate negative relationship between the change in grip strength and the average riding HR and Q, which means that those riders who had significantly greater decrements of upper body muscular fatigue were more likely to have higher riding HR. The resulting increase in blood pressure would cause an increase in vasoconstriction and this would increase the amount of blood returning to the heart (venous return) and EDV, so that $\mathrm{Q}$ is maintained ${ }^{43}$, even with a lower EF.

\subsection{Muscular Fatigue}

Snowmobiling significantly induced handgrip fatigue over the course of a condensed representative ride. Given that snowmobilers reported engaging in snowmobiling approximately 2 times per week, it is possible that this this observation of significant hand gripping demands might lead to a meaningful stress to the forearm musculature. Previous literature of isometric handgrip demonstrates that this type of training can have beneficial acute and chronic effects on blood pressure. Significant decreases in systolic blood pressure have been observed several hours post a single bout of isometric handgrip exercise ${ }^{87}$. With chronic training, 8 weeks of handgrip training were associated with a significant decrease of $7 \mathrm{mmHg}$ in systolic blood pressure and 4 $\mathrm{mmHg}$ in mean arterial pressure ${ }^{88}$. Similar training adaptations were noted after 12 weeks, as well as an improved endothelial-dependent vasodilation, as noted by the improved absolute and relative brachial artery flow-mediated dilation ${ }^{89}$. Both studies involved 3 weekly sessions of handgrip training. This suggests that snowmobiling could potentially improve blood pressure as well as increase forearm muscular strength, if participation is of a sufficient intensity and frequency.

Interestingly, BCR riders were unique in their lack of induced fatigue in grip strength. This could be due to the fact that riders were not climbing significant hills or lower average riding speed as the representative course was more technical, which would require riders to slow 
down to navigate tight turns or other obstacles. It also suggests that, perhaps, it is not the act of steering itself that leads to fatigue, but rather a gripping effect, which may have differed between sites. Similar to the other terrains, there was a lack of change in jump power observed in the BCR riders, which suggests that the lower body was not sufficiently fatigued to reduce jumping ability or that a lower body muscular power test may be inappropriate for the measurement of muscle fatigue in snowmobile riders.

\subsection{Body position while riding}

$\mathrm{BCR}$ riders were similar to FL riders in the percentage of a ride spent sitting or standing, however, it is important to note that BCR riders had larger standard inter-individual variation (highest standard deviation for percentage sitting, standing and standing time on perturbed terrain). It is unclear whether this discrepancy is due to the inherent variability of riding style, or whether the sample population was too small. BCR riders stood less, sat more, and were on undulating terrain significantly longer than MN riders. Given that metabolic data was not available for this type of terrain riding, it is interesting to speculate as to what the objective physical demand would have been as a result. This is an area that warrants further investigation.

\subsection{PA Adherence}

While markers of PA adherence were not incorporated in the current design, as it was not a longitudinal training study, it is important to make some inferences as a greater accumulation of activity time would only results from an individual consistently complying with an active lifestyle or exercise program. Snowmobiling is a varied and dynamic activity, involving excursions into different intensities, varying scenic views, and changing terrain features. This inherent variability is likely to increase adherence as the rider remains engaged throughout the ride and would be motivated to explore or ride new and different terrains. Similar improvements in adherence have been observed with interval training. Greater feelings of enjoyment postexercise are felt during interval training because of it is varied nature compared to the consistent

effort traditional training ${ }^{90}$. While snowmobile riding, higher intensity excursions comprised one fourth of total ride time at or above $60 \% \mathrm{VO}_{2} \mathrm{R}$ (high intensity) and one tenth at or above $80 \%$ 
$\mathrm{VO}_{2} \mathrm{R}$ (very high intensity). Snowmobiling is similar to interval training in that there are small periods of higher intensities interspersed between longer periods of lower intensity recovery. Variation is critical for increased activity enjoyment and would likely lead to greater adherence

${ }^{90}$, which could possibly lead to a greater accumulation of activity time during winter. Although the potential benefits toward adherence are predicated on the fact that an individual has interest or becomes interested in the activity and has the means to cover the cost of participation (winter gear, snowmobile, permits, etc.).

\subsection{Limitations}

A limitation to postural measurements was that perturbations were only recorded when riding in a standing position, thus any seated perturbations would be disregarded. This limitation was somewhat mitigated by the fact that the inclination of a rider is to stand in response to perturbations to better absorb the impact. Since MN riders spent significantly more time standing it is difficult to determine whether MN riders were also on undulating terrain longer than FL riders as an actual terrain difference or due to the device's default. Another limitation of the current study was the low female sample size that precluded from meaningful sex-based comparisons. Impedance cardiography data was underpowered to find statistical significance, although the current study does suggest similar trends that have been observed in other OHV activities and this preliminary data suggests future study is warranted. Finally, the present study is limited by the 20 minutes sampling period for estimation of the physical demands as the fatigue would only apply to that particular duration. The current aerobic demand would have to be extrapolated over several hours of riding and it is likely that a rider would not be able to maintain higher intensities for as long. Due to this short duration or the bias of participating in a "health study", riders might have been more inclined to ride more vigorously, in an attempt to influence the recorded intensity. This study does accurately depict snowmobiling as the intensity does vary more than previously thought. 


\section{Chapter 7: Conclusion}

In summary, the main novel finding of this thesis is that snowmobiling is a moderate intensity activity that requires meaningful aerobic effort and induces muscular fatigue, thus it could assist in the accumulation of physical activity time if done at a sufficient intensity and frequency. Snowmobiling may also provide increased health benefits by encouraging/requiring non-riding physical activity, thus increasing NEAT through the completion of tasks like digging out a stuck snowmobile, clearing brush, or lifting the track end of frozen, stuck, or parked snowmobiles. While riding, there are infrequent excursions into higher intensity zones, and these changes in intensity increase variation and may lead to greater exercise adherence. Vast differences exist in the physical demands of snowmobile riding based on terrain and location, which should be considered when determining total weekly physical activities. In fact, flatland riding confirms the previous estimate of the aerobic demand of snowmobiling (at 3.5 METs), while mountain riding was measured at double that of flatland riding. It is also likely that an individual can self-select a higher intensity to ensure greater health benefits by choosing more technical terrain or trails, and by consciously spending more time standing, transitioning from different postures, or actively gripping the handlebar more forcefully. While snowmobile riding may not confer the health benefits of higher-intensity exercise, it should be considered a beneficial addition to an individual's weekly accumulation of moderate PA. The discourse around snowmobile riding should therefore encourage riders to not only pursue snowmobiling for enjoyment, but also for the physical and mental health benefits that such PA confers. 


\section{REFERENCES}

1. Katch VL, McArde WD, Katch FI. Essentials of Exercise Physiology. Lippincott Williams \& Wilkins; 2011.

2. Neufer PD, Bamman MM, Muoio DM, et al. Understanding the Cellular and Molecular Mechanisms of Physical Activity-Induced Health Benefits. Cell Metab. 2015;22(23):4-11.

3. Lear SA, Hu W, Rangarajan S, et al. The effect of physical activity on mortality and cardiovascular disease in 130000 people from 17 high-income, middle-income, and lowincome countries: the PURE study. Lancet. 2017;390(10113):2643-2654.

4. Hu G, Qiao Q, Silventoinen K, et al. Occupational, commuting, and leisure-time physical activity in relation to risk for Type 2 diabetes in middle-aged Finnish men and women. Diabetologia. 2003;46(3):322-329.

5. Garfinkel L, Stellman SD. Mortality by relative weight and exercise. Cancer. 1988;62(S1):1844-1850.

6. Hassmén P, Ceci R, Bäckman L. Exercise for older women: a training method and its influences on physical and cognitive performance. Eur J Appl Physiol Occup Physiol. 1992;64(5):460-466.

7. Pescatello LS, Arena R, Riebe D, Thompson PD. ACSM's Guidelines for Exercise Testing and Prescription. Philadelphia, PA: Wolters Kluwer/Lippincott Williams \& Wilkins Health; 2006.

8. Tremblay MS, Warburton DE, Janssen I, et al. New Canadian Physical Activity Guidelines. Appl Physiol Nutr Metab. 2011;36:36-46.

9. Organization WH. Global Recommendations on Physical Activity for Health. Geneva, Switzerland; 2010.

10. Guthold R, Stevens GA, Riley LM, Bull FC. Worldwide trends in insufficient physical activity from 2001 to 2016: a pooled analysis of 358 population-based surveys with 1.9 million participants. Lancet Glob Heal. 2018;6(10):e1077-e1086.

11. Colley RC, Carson V, Garriguet D, Janssen I, Roberts KC, Tremblay MS. Physical activity of Canadian children and youth, 2007 to 2015. Heal Reports. 2017;28(10):8-16.

12. Ding D, Lawson KD, Kolbe-Alexander TL, et al. The economic burden of physical inactivity: a global analysis of major non-communicable diseases. Lancet. 2016;388:13111324.

13. Booth FW, Chakravarthy M V. Cost and consequences of sedentary living new battleground for an old enemy. Res Dig. 2002;3(16). 
14. Warburton DER, Katzmarzyk PT, Rhodes RE, et al. Evidence-informed physical activity guidelines for Canadian adults. Can J Public Heal Appl Physiol Nutr Metab J Public Heal Appl Physiol Nutr Metab. 2007;32(32):16-68.

15. Carnethon MR, Gulati M, Greenland P. Prevalence and cardiovascular disease correlates of low cardiorespiratory fitness in adolescents and adults. $J$ Am Med Assoc. 2005;294(23):2981-2988.

16. Center for Disease Control. Promoting Physical Activity: A Guide for Community Action. 1st ed. Illinois: Human Kinetics; 1999.

17. Pivarnik JM, Reeves MJ, Raferty ANNP. Seasonal Variation in Adult Leisure-Time Physical Activity. Med Sci Sport Exerc. 2003;35(6):1004-1008.

18. Dannenberg AL, Keller JB, Wilson PW, Castelli WP. Leisure time physical activity in the Framingham Offspring Study. Description, seasonal variation, and risk factor correlates. Am J Epidemiol. 1989;129(1):76-88.

19. Canadian Council of Snowmobile Organizations. Snowmobiling by the Numbers.; 2016. http://www.ccso-ccom.ca/wp-content/uploads/2016/01/Snowmobiling-by-the-NumbersMay-2016.pdf. Accessed August 7, 2018.

20. Jefferis BJ, Parsons TJ, Sartini C, et al. Does duration of physical activity bouts matter for adiposity and metabolic syndrome? A cross-sectional study of older British men. Int J Behav Nutr Phys Act. 2016;13(1):36.

21. Butcher LR, Thomas A, Backx K, Roberts A, Webb R, Morris K. Low-intensity exercise exerts beneficial effects on plasma lipids via ppar?? Med Sci Sports Exerc.

2008;40(7):1263-1270.

22. Salmon J, Owen N, Crawford D, Bauman A, Sallis JF. Physical activity and sedentary behavior: A population-based study of barriers, enjoyment, and preference. Heal Psychol. 2003;22(2):178-188.

23. Júdice PB, Hamilton MT, Sardinha LB, Zderic TW, Silva AM. What is the metabolic and energy cost of sitting, standing and sit/stand transitions? Eur J Appl Physiol. 2016;116(2):263-273.

24. Dunstan DW, Kingwell BA, Larsen R, et al. Breaking up prolonged sitting reduces postprandial glucose and insulin responses. Diabetes Care. 2012;35(5):976-983.

25. Peddie MC, Bone JL, Rehrer NJ, Skeaff CM, Gray AR, Perry TL. Breaking prolonged sitting reduces postprandial glycemia in healthy, normal-weight adults: A randomized crossover trial. Am J Clin Nutr. 2013;98(2):358-366.

26. Levine JA, Vander Weg MW, Hill JO, Klesges RC. Non-exercise activity thermogenesis: 
The crouching tiger hidden dragon of societal weight gain. Arterioscler Thromb Vasc Biol. 2006;26(4):729-736.

27. Ainsworth BE, Haskell WL, Herrmann SD, et al. 2011 Compendium of Physical Activities: a second update of codes and MET values. Med Sci Sports Exerc. 2011;43(8):1575-1581.

28. Cunha FA, Midgley AW, Montenegro R, Oliveira RB, Farinatti PTV. Metabolic equivalent concept in apparently healthy men: a re-examination of the standard oxygen uptake value of $3.5 \mathrm{~mL} \cdot \mathrm{kg}-1 \cdot \mathrm{min}-1$. Appl Physiol Nutr Metab. 2013;38(11):1115-1119.

29. Ázara HM, Farinatti PTV, Midgley AW, Vasconcellos F, Vigário P, Cunha FA. Standardized MET Value Underestimates the Energy Cost of Treadmill Running in Men. Int J Sports Med. 2017;38(12):890-896.

30. Westerling D. A study of physical demands in riding. Eur J Appl Physiol Occup Physiol. 1983;50(3):373-382.

31. Beale L, Maxwell NS, Gibson OR, Twomey R, Taylor B, Church A. Oxygen Cost of Recreational Horse-Riding in Females. J Phys Act Heal. 2015;12(6):808-813.

32. Burr JF, Jamnik VK, Shaw JA, Gledhill N. Physiological demands of Off-road vehicle riding. Med Sci Sports Exerc. 2010;42(7):1345-1354.

33. Haskell WL, Lee I-M, Pate RR, et al. Physical Activity and Public Health: Updated Recommendation for Adults From the American College of Sports Medicine and the American Heart Association. Circulation. 2007;116(9):1081-1093.

34. Konttinen T, Häkkinen K, Kyröläinen H. Cardiopulmonary loading in motocross riding. $J$ Sports Sci. 2007;25(9):995-999.

35. Tinken TM, Thijssen DHJ, Hopkins N, Dawson EA, Cable NT, Green DJ. Shear stress mediates endothelial adaptations to exercise training in humans. Hypertens (Dallas, Tex 1979). 2010;55(2):312-318.

36. Shephard RJ, Aoyagi Y. Measurement of human energy expenditure, with particular reference to field studies: An historical perspective. Eur J Appl Physiol.

2012;112(8):2785-2815.

37. Melanson EL, Freedson PS, Hendelman D, Debold E. Reliability and validity of a portable metabolic measurement system. Can J Appl Physiol. 1996;21(2):109-119.

38. Freedson PS, Miller K. Objective monitoring of physical activity using motion sensors and heart rate. Res Q Exerc Sport. 2000;71:21-29.

39. Filaire E, Filaire M, Scanff C. Salivary cortisol, heart rate and blood lactate during a 
qualifying. J Sports Med Phys Fitness. 2007;47(4):413.

40. Ascensão A, Azevedo V, Ferreira R, Oliveira E, Marques F, Magalhães J. Physiological, biochemical and functional changes induced by a simulated 30 min off-road competitive motocross heat. J Sports Med Phys Fitness. 2008;48(3):311-319.

41. Schwaberger G. Heart rate, metabolic and hormonal responses to maximal psychoemotional and physical stress in motor car racing drivers. Int Arch Occup Environ Health. 1987;59(6):579-604.

42. Hjortskov N, Rissén D, Blangsted AK, Fallentin N, Lundberg U, Søgaard K. The Effect of Mental Stress on Heart Rate Variability and Blood Pressure During Computer Work. Artic Eur J Appl Physiol. 2004;92:84-89.

43. Smith, Denise L. Fernhall B. Advanced Cardiovascular Exercise Physiology. Human Kinetics; 2011.

44. Miller JC, Horvath SM. Impedance Cardiography. Psychophysiology. 1978;15(1):80-91.

45. Belardinelli R, Ciampani N, Costantini C, Blandini A, Purcaro A. Comparison of impedance cardiography with thermodilution and direct Fick methods for noninvasive measurement of stroke volume and cardiac output during incremental exercise in patients with ischemic cardiomyopathy. Am J Cardiol. 1996;77(15):1293-1301.

46. Scherhag A, Kaden JJ, Kentschke E, Sueselbeck T, Borggrefe M. Comparison of impedance cardiography and thermodilution-derived measurements of stroke volume and cardiac output at rest and during exercise testing. Cardiovasc Drugs Ther. 2005;19(2):141-147.

47. Sanna I, Pinna V, Milia R, et al. Hemodynamic Responses during Enduro-Motorcycling Performance. Front Physiol. 2017;8:1062. doi:10.3389/fphys.2017.01062

48. Nobrega ACL, O’Leary D, Silva BM, Marongiu E, Piepoli MF, Crisafulli A. Neural regulation of cardiovascular response to exercise: role of central command and peripheral afferents. Biomed Res Int. 2014;2014:478965.

49. Sloan RP, Shapiro PA, Bagiella E, Bigger JT, Lo ES, Gorman JM. Relationships between circulating catecholamines and low frequency heart period variability as indices of cardiac sympathetic activity during mental stress. Psychosom Med. 58(1):25-31.

50. Spencer FA, Goldberg RJ, Becker RC, Gore JM. Seasonal distribution of acute myocardial infarction in the second National Registry of Myocardial Infarction. J Am Coll Cardiol. 1998;31(6):1226-1233.

51. Auger N, Potter BJ, Smargiassi A, Bilodeau-Bertrand M, Paris C, Kosatsky T. Association between quantity and duration of snowfall and risk of myocardial infarction. CMAJ. 
2017;189(6):E235-E242.

52. Nakamoto M. Responses of sympathetic nervous system to cold exposure in vibration syndrome subjects and age-matched healthy controls. Int Arch Occup Env Heal. 1990;62(2):177-181.

53. Rintamäki H. Human responses to cold. Alaska Med. 2007;49(2 Suppl):29-31.

54. Hietanen E. Cardiovascular responses to static exercise. Scand J Work Environ Health. 1984;10(6):397-402.

55. World Health Organization. Depression and Other Common Mental Disorders: Global Health Estimates. Geneva, Switzerland; 2017.

56. Hartig T, Mang M, Evans GW. Restorative Effects of Natural Environment Experiences. Environ Behav. 1991;23(1):3-26.

57. Grahn P, Stigsdotter UA. Landscape planning and stress. Urban For Urban Green. 2003;2(1):1-18. doi:10.1078/1618-8667-00019

58. Barton J, Hine R, Pretty J. The health benefits of walking in greenspaces of high natural and heritage value. J Integr Environ Sci. 2009;6(4):261-278.

59. Thompson Coon J, Boddy K, Stein K, Whear R, Barton J, Depledge MH. Does participating in physical activity in outdoor natural environments have a greater effect on physical and mental wellbeing than physical activity indoors? A systematic review. Environ Sci Technol. 2011;45(5):1761-1772.

60. Bratman GN, Hamilton JP, Hahn KS, Daily GC, Gross JJ. Nature experience reduces rumination and subgenual prefrontal cortex activation. Proc Natl Acad Sci U S A. 2015;112(28):8567-8572. doi:10.1073/pnas.1510459112

61. Li Q, Kobayashi M, Kumeda S, et al. Effects of Forest Bathing on Cardiovascular and Metabolic Parameters in Middle-Aged Males. Evidence-based Complement Altern Med. 2016;2016:2587381.

62. Raap K. Facts and Myths About Snowmobiling and Winter Trails.; 2014.

63. Phillips DL. Mental health status, social participation, and happiness. J Health Soc Behav. 1967;8(4):285-291.

64. Beutel ME, Klein EM, Brähler E, et al. Loneliness in the general population: prevalence, determinants and relations to mental health. BMC Psychiatry. 2017;17(1):97.

65. Rico-Uribe LA, Caballero FF, Martín-María N, Cabello M, Ayuso-Mateos JL, Miret M. Association of loneliness with all-cause mortality: A meta-analysis. Jacobs JM, ed. PLoS 
One. 2018;13(1):e0190033.

66. Pels F, Kleinert J. Loneliness and physical activity: A systematic review. Int Rev Sport Exerc Psychol. 2016;9(1):231-260.

67. Hopman-Rock M, Westhoff MH. Development and Evaluation of "Aging Well and Healthily": A Health-Education and Exercise Program for Community-Living Older Adults. Chodzko-Zajko WJ, ed. J Aging Phys Act. 2002;10(4):364-381.

68. Kahlbaugh PE, Sperandio AJ, Carlson AL, Hauselt J. Effects of Playing Wii on WellBeing in the Elderly: Physical Activity, Loneliness, and Mood. Act Adapt Aging.

2011;35(4):331-344.

69. McAuley E, Blissmer B, Marquez DX, Jerome GJ, Kramer AF, Katula J. Social Relations, Physical Activity, and Well-Being in Older Adults. Prev Med (Baltim). 2000;31(5):608617.

70. Savikko N, Routasalo P, Tilvis R, Pitkälä K. Psychosocial group rehabilitation for lonely older people: favourable processes and mediating factors of the intervention leading to alleviated loneliness. Int J Older People Nurs. 2010;5(1):16-24.

71. Vanlaar W, McAteer H, Brown S, Crain J, McFaull S, Hing MM. Injuries related to offroad vehicles in Canada. Accid Anal Prev. 2015;75:264-271.

72. National Trauma Registry Analysis in Brief ATV Injury Hospitalizations in Canada, 2004-2005. 2007:1-19. www.cihi.ca. Accessed September 18, 2018.

73. Internation Snowmobile Manufacturers Association. Snowmobiling Fact Book. Haslett, Michigan USA; 2017. http://www.snowmobile.org/docs/isma-snowmobiling-factbook.pdf. Accessed April 25, 2018.

74. Brach JS, Simonsick EM, Kritchevsky S, Yaffe K, Newman AB. The Association Between Physical Function and Lifestyle Activity and Exercise in the Health, Aging and Body Composition Study. J Am Geriatr Soc. 2004;52(4):502-509.

75. Janssen I. Health care costs of physical inactivity in Canadian adults. Appl Physiol Nutr Metab. 2012;37(4):803-806.

76. Borg GA. Psychophysical bases of perceived exertion. Med Sci Sports Exerc. $1982 ; 14(5): 377-381$.

77. Astorino TA, Robergs RA, Ghiasvand F, Marks D, Burns S. Incidence Of The Oxygen Plateau at VO 2 max During Exercise Testing To Volitional Fatigue. An Int Electron J. 2000;3(4).

78. Swain DP. Energy cost calculations for exercise prescription: An update. Sport Med. 
2000;30(1):17-22.

79. Trosclair D; Bellar, D; Judge, L W; Smith, J; Mazerat, N; Brignac A. Hand-Grip Strength as a Predictor of Muscular Strength and E... : The Journal of Strength \&amp; Conditioning Research. J Strength Cond Res. 2011;25.

80. Sayers SP, Harackiewicz D V, Harman EA, Frykman PN, Rosenstein MT. Crossvalidation of three jump power equations. Med Sci Sports Exerc. 1999;31(4):572-577.

81. Sheel AW, Seddon N, Knight A, McKenzie DC, R Warburton DE. Physiological responses to indoor rock-climbing and their relationship to maximal cycle ergometry. Med Sci Sports Exerc. 2003;35(7):1225-1231.

82. Konttinen T, Kyröläinen H, Häkkinen K. Cardiorespiratory and Neuromuscular Responses to Motocross Riding. J Strength Cond Res. 2008;22(1):202-209.

83. MacDougall JD, Tuxen D, Sale DG, Moroz JR, Sutton JR. Arterial blood pressure response to heavy resistance exercise. J Appl Physiol. 1985;58(3).

84. Foster C, Florhaug JA, Franklin J, et al. A New Approach to Monitoring Exercise Training. J Strength Cond Res. 2001;15(1):109-115.

85. Rowell LB, Marx HJ, Bruce RA, Conn RD, Kusumi F. Reductions in cardiac output, central blood volume, and stroke volume with thermal stress in normal men during exercise. J Clin Invest. 1966;45(11):1801-1816.

86. Cui J, Mascarenhas V, Moradkhan R, Blaha C, Sinoway LI. Effects of muscle metabolites on responses of muscle sympathetic nerve activity to mechanoreceptor(s) stimulation in healthy humans. AJP Regul Integr Comp Physiol. 2007;294(2):R458-R466.

87. Van Assche T, Buys R, DE Jaeger M, Coeckelberghs E, Cornelissen V. One single bout of low intensity isometric handgrip exercise reduces blood pressure during daily activities in healthy pre- and hypertensive individuals. J Sports Med Phys Fitness. 2016;57(4):469475.

88. Carlson DJ, Inder J, Palanisamy SKA, McFarlane JR, Dieberg G, Smart NA. The efficacy of isometric resistance training utilizing handgrip exercise for blood pressure management: A randomized trial. Med (United States). 2016;95(52):e5791.

89. Badrov MB, Freeman SR, Zokvic MA, Millar PJ, McGowan CL. Isometric exercise training lowers resting blood pressure and improves local brachial artery flow-mediated dilation equally in men and women. Eur J Appl Physiol. 2016;116(7):1289-1296.

90. Bartlett JD, Close GL, Maclaren DPM, Gregson W, Drust B, Morton JP. High-intensity interval running is perceived to be more enjoyable than moderate-intensity continuous exercise: Implications for exercise adherence. J Sports Sci. 2011;29(6):547-553. 


\title{
APPENDICES
}

\section{Appendix A: REB Certification of Approval of Research}

\author{
UNIVERSITY RESEARCH ETHICS BOARDS \\ of GUELPH Certification of Ethical Acceptability of Research \\ Involving Human Participants

$\begin{array}{ll}\text { APPROVAL PERIOD: } & \text { November 30,2016 } \\ \text { EXPIRY DATE: } & \text { November 30,2017 } \\ \text { REB: } & \text { NPES } \\ \text { REB NUMBER: } & 160 \mathrm{CO} 012 \\ \text { TYPE OF REVIEW: } & \text { Full Board } \\ \text { PRINCIPAL INVESTIGATOR: } & \text { Burr, Jamie (burri@uoguelph.ca) } \\ \text { DEPARTMENT: } & \text { Human Health \& Nutritional Sciences } \\ \text { SPONSOR(S): } & \text { Canadian Council of Snowmobile Organizations } \\ \text { TITLE OF PROJECT: } & \text { Physiological demands of snow-mobile riding }\end{array}$ \\ The members of the University of Guelph Research Ethics Board have examined the protocol which \\ describes the participation of the human participants in the above-named research project and considers \\ the procedures, as described by the applicant, to conform to the University's ethical standards and the \\ Tri-Council Policy Statement, $2^{\text {nd }}$ Edition. \\ The REB requires that researchers: \\ - Adhere to the protocol as last reviewed and approved by the REB \\ - Receive approval from the REB for any modifications before they can be implemented. \\ - Report any change in the source of funding. \\ - Report unexpected events or incidental findings to the REB as soon as possible with an \\ indication of how these events affect, in the view of the Principal Investigator, the safety of the \\ participants, and the continuation of the protocol. \\ - Are responsible for ascertaining and complying with all applicable legal and regulatory \\ requirements with respect to consent and the protection of privacy of participants in the \\ jurisdiction of the research project. \\ The Principal Investigator must: \\ - Ensure that the ethical guidelines and approvals of facilities or institutions involved in the \\ research are obtained and filed with the REB prior to the initiation of any research protocols. \\ - Submit a Status Report to the REB upon completion of the project. If the research is a multi-year \\ project, a status report must be submitted annually prior to the expiry date. Failure to submit an \\ annual status report will lead to your study being suspended and potentially terminated. \\ The approval for this protocol terminates on the EXPIRY DATE, or the term of your appointment or \\ employment at the University of Guelph whichever comes first. \\ Signature: \\ Date: November 30, 2016

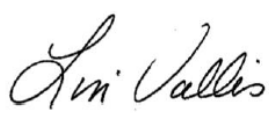 \\ L. Vallis \\ Chair, Research Ethics Board-NPES
}


Appendix B: Informed Consent

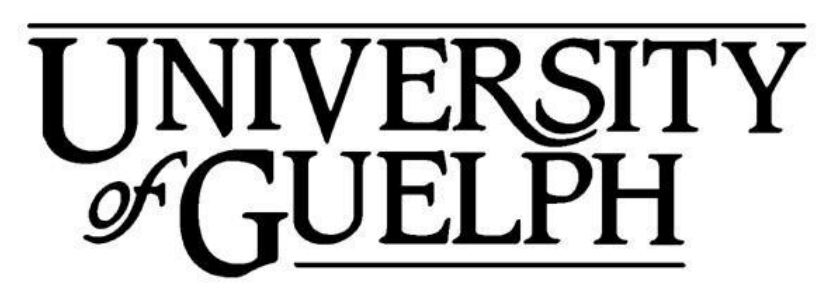

INFORMATION and CONSENT to PARTICIPATE in RESEARCH

\section{Physiological Assessment and Analysis of the Physical Demand of Riding a Snowmobile}

\section{REB\# 160C012}

\section{Investigators}

Tania Pereira, MSc. Candidate, Department of Human Health and Nutritional Sciences, University of Guelph, Contact: tperei01@uoguelph.ca

Jamie Burr, PhD, Assistant Professor. Department of Human Health and Nutritional Sciences, University of Guelph, Contact: burrj@uoguelph.ca

John Durocher, PhD, Assistant Professor. Department of Biological Sciences, Michigan Technological University, Contact: jiduroch@ mtu.edu

Trevor King, PhD, Post-doctoral researcher. Department of Human Health and Nutritional Sciences, University of Guelph, Contact: trevking@uoguelph.ca

\section{Introduction}

You are invited to participate in a research study conducted by the University of Guelph Human Performance Laboratory. The goal of the research project is to determine the physical demand and potential health benefits associated with snow mobile riding.

I am a master's student in the Department of Human Health and Nutritional Sciences at the University of Guelph and the information I am collecting will be used in my thesis.

We are exploring the physical demands of snowmobile riding, as there is no research that defines the demand put on the body for this activity. Physical activity is a critical aspect in the maintenance of health, if individuals are using snowmobiling as a mode of physical activity then there should be scientific research that can confirm whether participating in snowmobiling will be equal to participation in more traditional forms of physical activity like walking, sports, etc. The study will be using a portable system that measures the gases that you are breathing-out to estimate the oxygen cost of doing that activity. Those measurements will be compared to a 
traditional exercise test, a cycle test that uses slowly increasing pedal resistance, to determine the participant's level of fitness.

Winter time also can be an obstacle for participation in recreational exercise. Since snowmobiling is a winter activity, then it could potentially offer an alternative. This study will determine if there are health benefits associated with snow mobile riding so that individuals can make an informed decision when attempting to meet physical activity guidelines in the winter.

The study is being funded by the Canadian Council of Snowmobile Organizations (CCSO). The funder's role will be to give the research team access to snowmobile clubs, organizations and associations. The CCSO will also give us access to special snowmobile events to recruit potential participants in this study. The CCSO will also be providing us with well-maintained snowmobiles, access to snowmobile trails/ tracks for testing and establishing connections with the snow patrol emergency responders/ trail guides. The data collected during the course of this study will belong solely to the research team. The CCSO will not have any access to the data collected. The interpretation of these results and publication in a scientific journal will be at the sole discretion of the research team. The CCSO may choose to reference the results in future publications or public awareness campaigns.

If you are interested in participating in this investigation, please complete and sign the consent form. 


\section{Inclusion and Exclusion Criteria}

Inclusion

- Females and males between ages of 18-64

- Experienced snow mobile rider (Valid Driver's license or Snowmobile License)

- Able and willing to exercise

- Healthy as defined by the PARQ+ (Physical Activity Readiness Questionnaire - that determines if there are any other factors that could influence a person's ability to exercise safely)

\section{Exclusion}

- Chronic or acute injury/ disease affecting safe exercise participation as identified by the PARQ+ screening document

- Inability to safely operate a motor vehicle

- Impairment by drugs or alcohol

- Inability to abstain from using stimulants (coffee, nicotine), drugs and alcohol for at least 12 hours prior to testing and/or abstaining from strenuous activity for $>24 \mathrm{hr}$

The researchers which to be inclusive in their recruitment process. This project requires

- Interaction with one on one female researcher

- Wearing a mouthpiece while exercising

- Backpack-like straps to be placed around the shoulders

- Electrodes placed on the chest and neck (similar to an ECG used in a doctor's office to track electrical activity of the heart)

- Wearing a loose clothing base layer and all other gear associated with the activity (jacket, boots, etc.)

- Riding on a (approximate) 20 min snowmobile ride as well as participating in exercise tests

If for any reason you may feel uncomfortable taking part, please contact the researcher to discuss possible modifications to the procedure to address your concerns.

\section{Procedure}

This study will be performed in three locations, in the provinces of Quebec, British Colombia and Ontario.

If you volunteer to participate in this study, we will ask you to do the following:

We wish to measure the exertion that it takes to operate a snowmobile while you participate in a ride representative of your normal riding habits. This will take place during daylight hours only, and in safe weather conditions as determined by our trail guides and safety experts who are 
organizing the ride. You will be asked to wear loose clothing or shorts and a t-shirt as base layer for some initial measurements then regular weather protective gear for the snowmobile course.

Pre-course: Prior to participating in the snowmobile course, your height and weight will be measured while we set you up with our monitoring equipment. You will also perform a vertical jump test and a hand grip strength test. The vertical jump test will involve measuring your standing reach height (standing with shoulder touching the wall and reaching upwards with the hands) then preforming 3 jumps with hands outstretched to see how high you can reach, thus estimating leg power. The next test will be of grip strength, wherein a hand dynamometer will be squeezed, making a fist with your hand. We will record the maximal force you can exert with each hand. Following this, sticky electrodes will be placed on your chest under your base layer. After putting on all other layers, you will be asked to wear a backpack-like apparatus that will hold a mini console for analyzing the expired air that you breathe. It will be attached to a mouthpiece that is strapped to your head (see below) and worn under your helmet. If the apparatus does not fit into your own helmet, the research team will have a selection of different sized, approved, helmets into which the breathing apparatus can be fit.

Course: The snowmobiling course will incorporate approximately a 20-minute ride that includes various tasks like going uphill, downhill, and turning. You may also be asked to demonstrate other tasks commonly associated with regular snowmobiling, such as digging out your snowmobile. The track and tasks were determined by a survey of recreational snowmobilers to represent the average experience. The portable breath analyzer will continuously gather data as you do the activity but will in no way affect your ability to move freely or see out of the helmet. The face mask attached to the analyzer will be worn inside the helmet throughout the study, thus helmets fitted with the analyzer will be provided to you, if necessary. The mouthpiece will fit into the ventilator of the helmet, so the fit of the helmet will not change. It will also not impede any sight lines as the mouth piece is snug to your nose and mouth, leaving the visor vision field completely clear. Review the photo below to see how the devices are worn (Note: The face mask shown on the left will be used instead of the nose clip). 

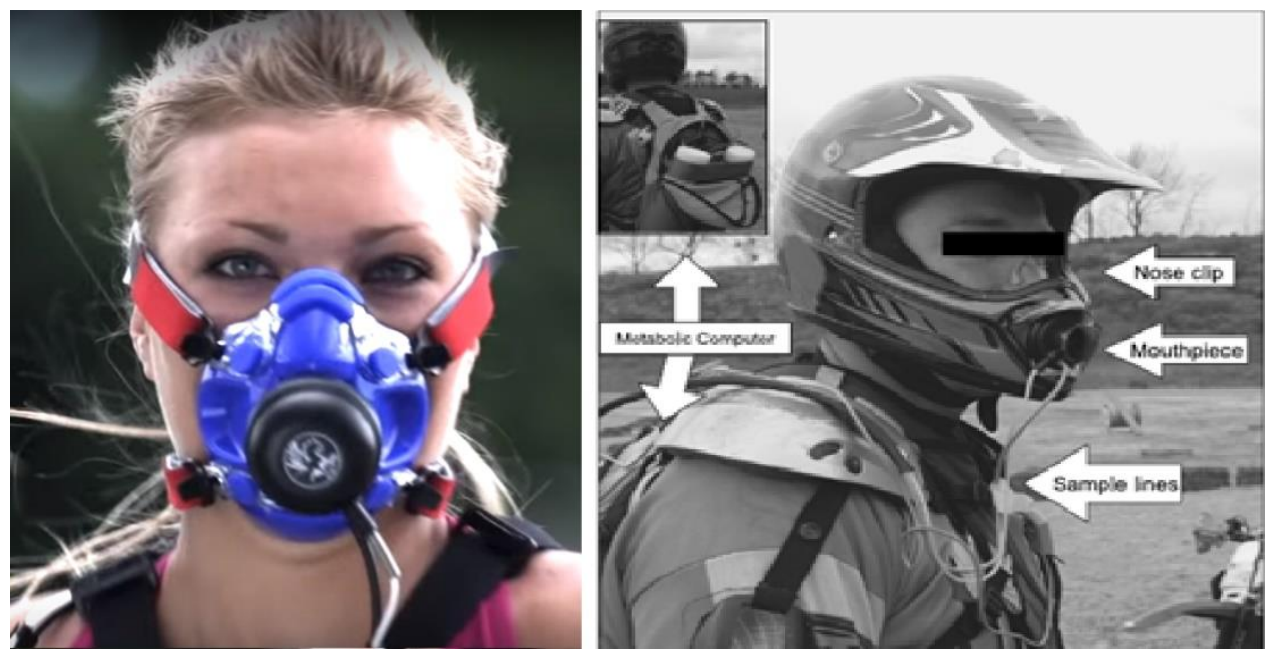

Post Course: Once you have completed the course you will be asked to repeat the vertical jump test and the hand grip strength test prior to resting. You will then change into clothing suitable for exercise and participate in a graded exercise test. The test will involve cycling on a Velotron (electronic bike) for upwards of 15 minutes. At predetermined intervals, the test will increase in difficulty by increasing the resistance that you are pedaling against. The test will end when the participant can no longer keep up with the pace, if the participant is experiencing any negative contraindications to exercise or if the participant would like to stop.

Total time requirement: 1.5 hours.

\section{$\underline{\text { Potential Risks and Discomforts }}$}

The physical fitness test and snowmobiling course may cause you to become tired and short of breath for a brief period of time. You will be at no greater risk at any time during the ride while we are monitoring exertion than at any other time you choose to participate in this activity recreationally. If anything, participation in the study will increase safety as you will be operating on a controlled, closed-course, track with well-trained medical/first aid emergency responders in attendance. There are no permanent known adverse side effects that are due to the exercise sessions to which you will be exposed, including both the snow mobile ride, and the fitness test. Data from typically older individuals with or without heart disease indicates that the likelihood of having a heart attack or dying during an exercise stress test is 1 in 10,000 tests during maximal exercise testing. All exercise testing and body composition measures will be performed under the supervision of trained personnel including a certified exercise physiologist (Canadian Society of Exercise Physiology (CSEP)). A CSEP-Certified Exercise Physiologist is a universitytrained individual that has obtained the most advanced health and fitness certification in Canada for work with healthy and clinical populations. They are trained, certified, and insured to conduct the appraisals outlined in this proposal.

There is some potential of discomfort from wearing the electrodes, the mouthpiece for the exercise testing. The electrodes are similar to those used by physicians in a doctor's office, there may be some pain associated with excess hair, so the participant can feel free to shave that area if 
preferred to reduce the risk of discomfort. Wearing the mouthpiece feels similar to cupping one's hands over your nose and mouth - or like the fog deflector commonly incorporated in many snowmobile helmets to prevent your breath from condensing inside the visor. Some heat and water vapor may be retained near your face, and some people may find this slightly claustrophobic, but there are no lasting effects of use. A shear will be provided to the participant upon request and will be sanitized prior to/ after use.

\section{Potential Benefits}

You may benefit from this study in gaining unique information about your current state of fitness, which requires expensive equipment and expertise to operate. We will be happy to share your own personal data with you. Your participation will also add to the body of knowledge concerning a sport that you choose to participate in.

\section{$\underline{\text { Data }}$}

Every effort will be made to ensure confidentiality of personal information that is obtained in connection with this study. Confidentiality will be secured by the use of participant ID Codes on all correspondence. Data will be kept on a password-protected computer and all written material secured indefinitely in a locked cabinet on site.

Data will be retained for 5 years for possible use for future analysis for the lab group in the case the project may be expanded upon (i.e. the student investigator may pursue a 4-year $\mathrm{PhD}$ expanding on this project). However, if you are deemed ineligible to participate, all healthrelated information and information obtained will be immediately destroyed. All data will be stored electronically in databases with access only granted to investigators involved in the use of the data. All personal identifiers will be destroyed following the study completion. Jamie Burr, $\mathrm{PhD}$, Assistant Professor will be in charge of data stewardship.

\section{Rights and Welfare of the Individual}

Your confidentiality will be respected. You have the right to refuse to participate in this study. It is understood that you are free to withdraw from any or all parts of the study at any time without penalty. You also have the right to not answer any questions you are uncomfortable answering or simply do not want to answer; you will not be penalized for your decision. Your identity will remain confidential as all individual records and results will be analyzed and referred to by number code only and kept in a locked cabinet in the Human Performance Laboratory at the University of Guelph. This lab will remain locked and only those directly involved in the study (namely Dr. Jamie Burr) will have access to your records and results. You will not be referred to by name in any study reports or research papers. Your individual results will remain confidential, as they will not be discussed with anyone outside the research team. This project was reviewed by the Research Ethics Board for compliance with federal guidelines for research involving human participants. If you have any questions regarding your rights and welfare as a research participant in this study (REB \#), please contact: Director, Research Ethics; University of 
Guelph; reb@uoguelph.ca; 519-824-4120 ext. 56606. You do not waive any legal rights by agreeing to take part in this study.

Please be assured that you may ask questions at any time. We will be glad to discuss your results with you when they have become available and we welcome your comments and suggestions. Should you have any concerns about this study or wish further information, please contact Dr. Jamie Burr(burrj@uoguelph.ca) at the University of Guelph. 


\section{SIGNATURE of RESEARCH PARTICIPANT}

I have read the information provided for the study "Physiological Assessment and Analysis of the Physical Demands of Riding a Snowmobile" as described herein. My questions have been answered to my satisfaction, and I agree to participate in this study. I have been given a copy of this form.

Name of Participant (please print)

Signature of Participant Date

SIGNATURE OF WITNESS

Name of Witness (please print)

Signature of Witness Date

** Please feel free to print the consent document and keep a copy for your records. 


\section{Appendix C: PARQ+ Form}

\section{PAR-Q+}

The Physical Activity Readiness Questionnaire for Everyone

The health benefits of regular physical activity are clear; more people should engage in physical activity every day of the week. Participating in physical activity is very safe for MOST people. This questionnaire will tell you whether it is necessary for you to seek further advice from your doctor OR a qualified exercise professional before becoming more physically active.

\begin{tabular}{|c|c|c|}
\hline \multicolumn{3}{|l|}{ GENERAL HEALTH QUESTIONS } \\
\hline Please read the 7 questions below carefully and answer each one honestly: check YES or NO. & YES & No \\
\hline 1) Has your doctor ever said that you have a heart condition $\square$ or high blood pressure $\square$ ? & $\square$ & $\square$ \\
\hline $\begin{array}{l}\text { 2) Do you feel pain in your chest at rest, during your daily activities of living, OR when you do } \\
\text { physical activity? }\end{array}$ & $\square$ & $\square$ \\
\hline $\begin{array}{l}\text { 3) Do you lose balance because of dizziness OR have you lost consciousness in the last } 12 \text { months? } \\
\text { Please answer NO if your dizziness was associated with over-breathing (including during vigorous exercise). }\end{array}$ & $\square$ & $\square$ \\
\hline $\begin{array}{l}\text { 4) Have you ever been diagnosed with another chronic medical condition (other than heart disease } \\
\text { or high blood pressure)? PLEASE LIST CONDITION(S) HERE: }\end{array}$ & $\square$ & $\square$ \\
\hline $\begin{array}{l}\text { 5) Are you currently taking prescribed medications for a chronic medical condition? } \\
\text { PLEASE LIST CONDITION(S) AND MEDICATIONS HERE: }\end{array}$ & $\square$ & $\square$ \\
\hline $\begin{array}{l}\text { 6) Do you currently have (or have had within the past } 12 \text { months) a bone, joint, or soft tissue } \\
\text { (muscle, ligament, or tendon) problem that could be made worse by becoming more physically } \\
\text { active? Please answer NO if you had a problem in the past, but it does not limit your current ability to be physically active. } \\
\text { PLEASE LIST CONDITION(S) HERE: }\end{array}$ & $\square$ & \\
\hline 7) Has your doctor ever said that you should only do medically supervised physical activity? & $\square$ & $\square$ \\
\hline
\end{tabular}

If you answered NO to all of the questions above, you are cleared for physical activity.

Go to Page 4 to sign the PARTICIPANT DECLARATION. You do not need to complete Pages 2 and 3.

D Start becoming much more physically active - start slowly and build up gradually.

- Follow International Physical Activity Guidelines for your age (www.who.int/dietphysicalactivity/en/).

- You may take part in a health and fitness appraisal.

If you are over the age of $45 \mathrm{yr}$ and NOT accustomed to regular vigorous to maximal effort exercise, consult a qualified exercise professional before engaging in this intensity of exercise.

If you have any further questions, contact a qualified exercise professional.

If you answered YES to one or more of the questions above, COMPLETE PAGES 2 AND 3.

Delay becoming more active if:

You have a temporary illness such as a cold or fever; it is best to wait until you feel better.

You are pregnant - talk to your health care practitioner, your physician, a qualified exercise professional, and/or complete the ePARmed-X+ at www.eparmedx.com before becoming more physically active.

Your health changes - answer the questions on Pages 2 and 3 of this document and/or talk to your doctor or a qualified exercise professional before continuing with any physical activity program.

OTOSHF $c$ copright @ 2016 PAR-Q+ Collaboration $1 / 4$ 


\section{PAR-Q+}

6. Do you have any Mental Health Problems or Learning Difficulties? This includes Alzheimer's, Dementia, Depression, Anxiety Disorder, Eating Disorder, Psychotic Disorder, Intellectual Disability, Down Syndrome

If the above condition(s) is/are present, answer questions $6 \mathrm{a}-6 \mathrm{~b}$ If No $\square$ go to question 7

6a. Do you have difficulty controlling your condition with medications or other physician-prescribed therapies? (Answer NO if you are not currently taking medications or other treatments)

6b. Do you have Down Syndrome AND back problems affecting nerves or muscles?

YES $\square$ NO $\square$

7. Do you have a Respiratory Disease? This includes Chronic Obstructive Pulmonary Disease, Asthma, Pulmonary High Blood Pressure

If the above condition(s) is/are present, answer questions 7a-7d

If NO $\square$ go to question 8

7a. Do you have difficulty controlling your condition with medications or other physician-prescribed therapies? (Answer NO if you are not currently taking medications or other treatments)

7b. Has your doctor ever said your blood oxygen level is low at rest or during exercise and/or that you require supplemental oxygen therapy?

YES $\square$ NO

7c. If asthmatic, do you currently have symptoms of chest tightness, wheezing, laboured breathing, consistent cough (more than 2 days/week), or have you used your rescue medication more than twice in the last week?

YES $\square$ NO

7d. Has your doctor ever said you have high blood pressure in the blood vessels of your lungs? YES $\square$ NO

8. Do you have a Spinal Cord Injury? This includes Tetraplegia and Paraplegia If the above condition(s) is/are present, answer questions $8 \mathrm{a}-8 \mathrm{c}$

If No $\square$ go to question 9

\begin{tabular}{ll} 
8a. & $\begin{array}{l}\text { Do you have difficulty controlling your condition with medications or other physician-prescribed therapies? } \\
\text { (Answer NO if you are not currently taking medications or other treatments) }\end{array}$ \\
\hline 8b. $\quad \begin{array}{l}\text { Do you commonly exhibit low resting blood pressure significant enough to cause dizziness, light-headedness, } \\
\text { and/or fainting? }\end{array}$ \\
\hline 8c. $\quad \begin{array}{l}\text { Has your physician indicated that you exhibit sudden bouts of high blood pressure (known as Autonomic } \\
\text { Dysreflexia)? }\end{array}$
\end{tabular}

9. Have you had a Stroke? This includes Transient Ischemic Attack (TIA) or Cerebrovascular Event If the above condition(s) is/are present, answer questions 9a-9c If NO $\square$ go to question 10

9a. Do you have difficulty controlling your condition with medications or other physician-prescribed therapies? (Answer NO if you are not currently taking medications or other treatmen

9b. Do you have any impairment in walking or mobility?

9c. Have you experienced a stroke or impairment in nerves or muscles in the past 6 months? YES $\square$ NO $\square$

10. Do you have any other medical condition not listed above or do you have two or more medical conditions? If you have other medical conditions, answer questions 10a-10c

If No $\square$ read the Page 4 recommendations

10a. Have you experienced a blackout, fainted, or lost consciousness as a result of a head injury within the last 12 months OR have you had a diagnosed concussion within the last 12 months?

10b. Do you have a medical condition that is not listed (such as epilepsy, neurological conditions, kidney problems)? YES $\square$ No $\square$

10c. Do you currently live with two or more medical conditions?

YES $\square$ NO

PLEASE LIST YOUR MEDICAL CONDITION(S)

AND ANY RELATED MEDICATIONS HERE:

\section{GO to Page 4 for recommendations about your current medical condition(s) and sign the PARTICIPANT DECLARATION.}




\section{PAR-Q+}

\section{If you answered NO to all of the follow-up questions about your medical condition,}

you are ready to become more physically active - sign the PARTICIPANT DECLARATION below: It is advised that you consult a qualified exercise professional to help you develop a safe and effective physical
activity plan to meet your health needs.

- You are encouraged to start slowly and build up gradually - 20 to 60 minutes of low to moderate intensity exercise, 3-5 days per week including aerobic and muscle strengthening exercises.

- As you progress, you should aim to accumulate 150 minutes or more of moderate intensity physical activity per week.

- If you are over the age of $45 \mathrm{yr}$ and NOT accustomed to regular vigorous to maximal effort exercise, consult a qualified exercise professional before engaging in this intensity of exercise.

If you answered YES to one or more of the follow-up questions about your medical condition: You should seek further information before becoming more physically active or engaging in a fitness appraisal. You should complete the specially designed online screening and exercise recommendations program - the ePARmed-X+ at www.eparmedx.com and/or visit a qualified exercise professional to work through the ePARmed- $X+$ and for further information.

$\triangle$ Delay becoming more active if:

You have a temporary illness such as a cold or fever; it is best to wait until you feel better.

You are pregnant - talk to your health care practitioner, your physician, a qualified exercise professional, and/or complete the ePARmed-X+ at www.eparmedx.com before becoming more physically active.

Your health changes - talk to your doctor or qualified exercise professional before continuing with any physical activity program.

- You are encouraged to photocopy the PAR-Q+. You must use the entire questionnaire and NO changes are permitted.

- The authors, the PAR-Q+ Collaboration, partner organizations, and their agents assume no liability for persons who undertake physical activity and/or make use of the PAR-Q+ or ePARmed-X+. If in doubt after completing the questionnaire, consult your doctor prior to physical activity.

\section{PARTICIPANT DECLARATION}

- All persons who have completed the PAR-Q+ please read and sign the declaration below.

- If you are less than the legal age required for consent or require the assent of a care provider, your parent, guardian or care provider must also sign this form.

I, the undersigned, have read, understood to my full satisfaction and completed this questionnaire. I acknowledge that this physical activity clearance is valid for a maximum of 12 months from the date it is completed and becomes invalid if my condition changes. I also acknowledge that a Trustee (such as my employer, community/fitness centre, health care provider, or other designate) may retain a copy of this form for their records. In these instances, the Trustee will be required to adhere to local, national, and international guidelines regarding the storage of personal health information ensuring that the Trustee maintains the privacy of the information and does not misuse or wrongfully disclose such information.

NAME

SIGNATURE
DATE

WITNESS

SIGNATURE OF PARENT/GUARDIAN/CARE PROVIDER

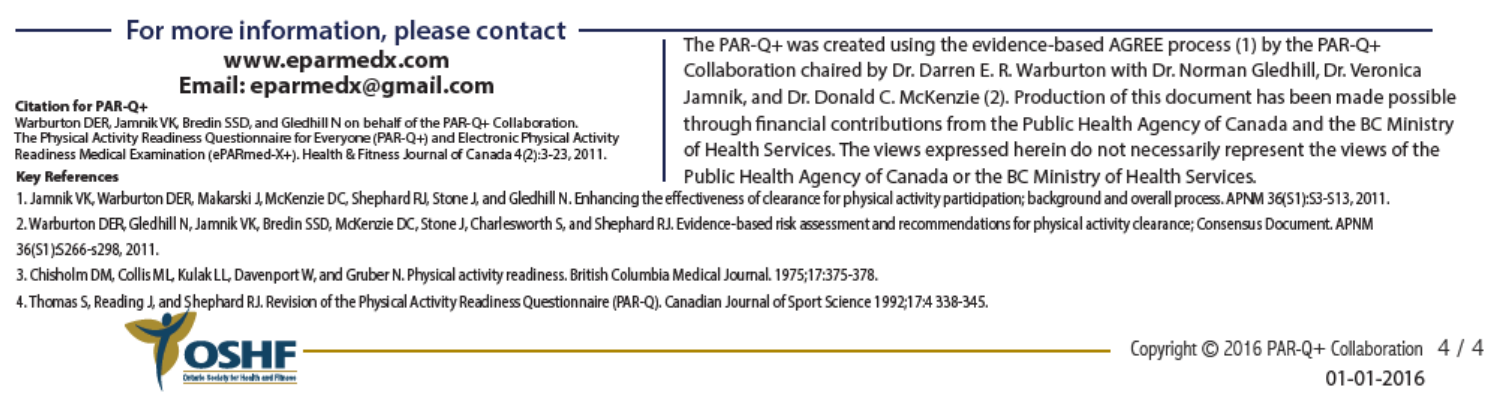


Appendix D: Snowmobile Survey \& Survey Consent

Q1

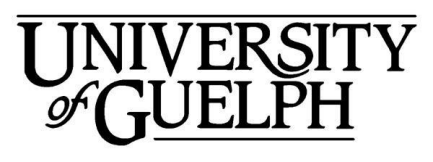

CONSENT TO PARTICIPATE IN RESEARCH

Physiological Assessment and Analysis of the Physical Demand of Riding a Snowmobile

REB\# $160 \mathrm{OC} 12$

You are invited to participate in a research survey conducted by Dr. Jamie Burr, from the Human Health and Nutritional Science department at the University of Guelph. The results of this survey will contribute to the thesis project of Tania Pereira.

Purpose: The purpose of this survey is to determine the average experience of a snowmobile ride. It will help us to determine your perceptions of the frequency, intensity, duration and type of physical demands that a rider is exposed to during the course of a normal snowmobile ride.

Funding: The study is being funded by the Canadian Council of Snowmobile Organizations (CCSO). The funder's role will be to give the research team access to equipment for a related analysis of the physical demand of riding. The use of this data for research purposes will be done at arms-length to the funder. The interpretation of these results and publication in a scientific journal will be at the sole discretion of the research team. The results will be shared with the CCSO at a formal presentation in June of 2017. The CCSO may choose to reference the results in future publications or public awareness campaigns.

Survey Time: If you participate in this study, you will be asked to answer the following questionnaire consisting of approximately 40 questions. It should take approximately 15-20 minutes to complete.

Survey Participation: There is little to no potential for risk associated with participating in this survey. We will not ask you for any personal information such as your name, contact information, etc. All responses will remain anonymous. However, due to the fact that data collection occurs via the internet, complete confidentiality of the data cannot be guaranteed. You can choose whether you would like to participate in the survey or not, and you may choose to skip any questions that you would prefer not to answer. If you volunteer to 
participate in this survey, you may withdraw or stop at any time without consequence. You may also exercise the option of removing your data from the survey.

If you have any questions or concerns about the survey, please feel free to contact the principal investigator: Jamie Burr or the student investigator: Tania Pereira by email at burrj@uoguelph.ca or tperei01@uoguelph.ca respectively.

By choosing the "I agree" option, you are agreeing that you have read the information provided for the survey as described herein and that you agree to participate in this survey. Do you agree or disagree to participating in this survey?

Yes, I agree to participate in this survey (1)

No, I disagree and do not wish to participate in this survey (2)

If No, I disagree and do not w... Is Selected, Then Skip to End of Survey

Q2 What is your sex?

O Male (1)

Female (2)

Q3 What is your age?

Q4 What is your height in feet and inches?

\begin{tabular}{|c|c|c|c|c|c|c|c|c|c|c|c|c|}
\hline & 0 & 1 & 2 & 3 & 4 & 5 & 6 & 7 & 8 & 9 & 10 & 11 \\
$(1)$ & $(15)$ & $(16)$ & $(17)$ & $(18)$ & $(19)$ & $(20)$ & $(21)$ & $(22)$ & $(23)$ & $(24)$ & $(25)$ \\
\hline Feet (1) & 0 & 0 & 0 & 0 & 0 & 0 & 0 & 0 & 0 & 0 & 0 & 0 \\
$\begin{array}{c}\text { Inch(es) } \\
(2)\end{array}$ & 0 & 0 & 0 & 0 & 0 & 0 & 0 & 0 & 0 & 0 & 0 & 0 \\
\hline
\end{tabular}

Q5 What is your weight in pounds (lb)?

Q6 What country do you live in?

Canada (1)

United States (2)

If Canada Is Selected, Then Skip to What province do you live in? If United States Is Selected, Then Skip to Which state do you live in? 
Q7 What province/ territory do you live in?

O Alberta (1)

O British Columbia (2)

O Manitoba (3)

O New Brunswick (4)

O Newfoundland and Labrador (5)

O Nova Scotia (6)

O Ontario (7)

O Prince Edward Island (8)

O Quebec (9)

O Saskatchewan (10)

O Northwest Territories (11)

O Nunavut (12)

O Yukon (13)

Q8 Which state do you live in?

O Alabama (1)

O Alaska (2)

O Arizona (3)

O Arkansas (4)

O California (5)

O Colorado (6)

O Connecticut (7)

O Delaware (8)

O Florida (9)

O Georgia (10)

O Hawaii (11)

O Idaho (12)

O Illinois (13)

O Indiana (14)

O Iowa (15)

O Kansas (16)

O Kentucky (50)

O Louisiana (17)

O Maine (18)

O Maryland (19)

O Massachusetts (20)

O Michigan (21) 
O Minnesota (22)

O Mississippi (23)

O Missouri (24)

O Montana (25)

O Nebraska (26)

O Nevada (27)

O New Hampshire (28)

O New Jersey (29)

O New Mexico (30)

New York (31)

North Carolina (32)

O North Dakota (33)

O Ohio (34)

O Oklahoma (35)

O Oregon (36)

O Pennsylvania (37)

O Rhode Island (38)

South Carolina (39)

O South Dakota (40)

O Tennessee (41)

Texas (42)

Utah (43)

Vermont (44)

Virginia (45)

Washington (46)

West Virginia (47)

Wisconsin (48)

Wyoming (49)

Q9 Where do you snowmobile the majority of the time?

Alabama (1)

O Alaska (6)

Alberta (7)

Arizona (8)

O Arkansas (9)

British Columbia (10)

California (11)

Colorado (12) 
O Connecticut (13)

O Delaware (14)

O Florida (15)

O Georgia (16)

O Hawaii (17)

O Idaho (18)

O Illinois (19)

O Indiana (20)

O Iowa (21)

O Kansas (22)

O Kentucky (23)

O Louisiana (24)

O Maine (25)

O Maryland (26)

O Massachusetts (27)

O Michigan (28)

O Minnesota (29)

O Mississippi (30)

O Missouri (31)

O Montana (32)

O Manitoba (2)

O Nebraska (33)

O Nevada (34)

O New Brunswick (35)

O Newfoundland \& Labrador (3)

O New Hampshire (4)

O New Jersey (36)

O New Mexico (37)

O New York (38)

O North Carolina (39)

O North Dakota (40)

O Northwest Territories (41)

O Nova Scotia (5)

O Nunavut (42)

O Ohio (43)

O Oklahoma (44)

O Ontario (45)

O Oregon (46)

O Pennsylvania (47) 
O Prince Edward Island (48)

O Quebec (49)

O Rhode Island (50)

O Saskatchewan (51)

O South Carolina (52)

O South Dakota (53)

O Tennessee (54)

O Texas (55)

O Utah (56)

O Vermont (57)

O Virginia (58)

O Washington (59)

O West Virginia (60)

O Wisconsin (61)

O Wyoming (62)

O Yukon (63)

Q10 Compared to other individuals of the same age, do you consider yourself?

O Less fit (1)

O The same (2)

O More fit than others (3)

Q11 In a week, how often do you participate in moderate to vigorous activity (Activities that increases difficulty of breathing or increases sweating)?

O 30 minutes a week (1)

O 60 minutes a week (2)

O 120 minutes a week (3)

$\mathrm{O}+120$ minutes a week (4)

Q12 How many years have you been snowmobiling for? (For example, 2 and a half years would be 2.5)

Q13 How difficult do you think snowmobiling is compared to other activities?

O Extremely easy (1)

O Moderately easy (2)

O Slightly easy (3)

O Neither easy nor difficult (4)

O Slightly difficult (5) 
Moderately difficult (6)

Extremely difficult (7)

Q14 What temperature do you find the most physically demanding when you are snowmobiling?

Temperature does not affect riding (2)

O 0 to $-5{ }^{\circ} \mathrm{C} / 32$ to $23{ }^{\circ} \mathrm{F}(1)$

O -5 to $-10{ }^{\circ} \mathrm{C} / 23$ to $14{ }^{\circ} \mathrm{F}(11)$

O -10 to $-15^{\circ} \mathrm{C} / 14$ to $5{ }^{\circ} \mathrm{F}(30)$

O -15 to $-20{ }^{\circ} \mathrm{C} / 5$ to $-4{ }^{\circ} \mathrm{F}(29)$

O -20 to $-25{ }^{\circ} \mathrm{C} /-4$ to $-13{ }^{\circ} \mathrm{F}(3)$

O -25 to $-30{ }^{\circ} \mathrm{C} /-13$ to $-22{ }^{\circ} \mathrm{F}(9)$

O $-30{ }^{\circ} \mathrm{C} /-22^{\circ}$ plus $(10)$

Q15 Who do you ride with most often?

Friends (1)

Family (2)

Work colleagues (3)

Alone (4)

Q16 Do you ride 1-up or 2-up most often?

O 1-up (1)

O 2-up (2)

Q17 How many days of riding do you do each winter?

Q18 How would you describe your most common snowmobiling participation?

Single Day Ride (1)

Multiple Consecutive Day Rides (2)

Q19 What is the average length of a single ride (hours and minutes)? (for example, 1 hour and 30 minutes would be 1.5 , excluding time for meals, trail breaks $\&$ gas stops)
○ $0.5(1)$
○ 1 (2)
○ $1.5(3)$
○ 2 (4)
○ $2.5(5)$ 

O $3(6)$
O 3.5 (7)
O 4 (8)
O 4.5 (9)
O 5 (10)
O 5.5 (11)
O 6 (12)
O 6.5 (13)
O 7 (14)
○ 7.5 (15)
O 8 (16)
O 8.5 (17)
○ 9 (18)
○ 9.5 (19)
O 10 (20)
O 10.5 (21)
O 11 (22)
○ 11.5 (23)
O 12 (24)

Q21 How many days a week do you ride on average during the winter? Day(s) a week (1)

Q22 What is the average distance that you ride per season? (Please only fill one of the boxes below based on which measurement you use)

\# of $\mathrm{km}(1)$

OR \# of miles (2)

Q23 What is the average distance that you ride per day? (Please only fill one of the boxes below based on which measurement you use)

\# of $\mathrm{km}(1)$

OR \# of miles (2)

Q24 On an average ride, how would you describe the terrain you encounter most?

- Mountain (1)

Flat ground (2)

Undulating low to moderate hills (3) 
Q29 On an average ride, what percent of the time are you on flat ground or undulating terrain? The total must equal 100 $\%$ of time on flat ground (1) $\%$ of time on undulating ground (2)

Q25 What percentage of the time are you trail riding vs "back country" riding? The total must equal 100

$\%$ time trail riding (1)

$\%$ time back country riding (2)

Q26 When you are riding on trail, what \% of the time is that trail smooth or not smooth? The total must equal 100

$\%$ time groomed (1)

$\%$ time non-groomed (2)

Q27 On an average ride, what percentage of the time are you sitting versus standing? The total must equal 100

$\%$ Sitting time (1)

$\%$ Standing time (2)

Q28 On an average ride, what percent of the time are you riding uphill vs. riding downhill vs. riding a hill sideways vs. cornering? The total must equal 100

$\%$ of time downhill (1)

$\%$ of time uphill (2)

$\%$ of time sideways (3)

$\%$ of time cornering (4)

Q30 Do you usually wear or carry any gear on your person? (i.e. carrying supplies in a backpack)

Y Yes (1)

No (2)

If No Is Selected, Then Skip to on an average ride, how often do you ... 
Q31 What is the approximate weight of the gear you carry - apart from normal snowmobile clothing and a helmet?

O 0 -10lb (1)

O $10-201 b(2)$

20-30lb (3)

○ 40-50lb (4)

○ $50 \mathrm{lb}(5)$

Q32 On an average ride, how often do you have to dig out a snowmobile(s)?

$\begin{array}{ll} & 0(1) \\ \bigcirc & 1(2) \\ \bigcirc & 2(3) \\ \bigcirc & 3(4) \\ \bigcirc & 4+(5)\end{array}$

If 0 Is Selected, Then Skip to Are there any other physical demands ... 
Q33 How long does it usually take for you to dig out this snowmobile(s)?

Less than 5 minutes (1)

5-10 minutes (2)

O $10-15$ minutes (3)

O $15-20$ minutes (4)

20+ minutes (5)

Q34 On a scale of 1-10, how hard do you think digging out a snowmobile is physically? (0 being not at all physically challenging to 10 being out of breath and very physically challenging)

Difficulty of digging out (1)

Q35 If applicable, please select the ONE other physically most demanding activity of an average snowmobile ride:

Loading and unloading snowmobile(s) (1)

Pulling snowmobile(s) around at a gas station (3)

Lifting back end of snowmobile(s) to loosen snow and ice from track (4)

Towing a disable snowmobile (5)

Tipping snowmobile on its side to do repair or adjustment (6)

Changing drive belt (7)

Clearing the way ahead (8)

Other (9)

O N/A (2)

If N/A Is Selected, Then Skip to End of Survey

Display question if "If applicable, please select the ONE other physically most demanding activity of an average snowmobile ride" is answered by selecting: Other

Q36 What is that other physical demand of an average snowmobile ride?

Q37 on a scale of 1-10, how physically difficult is the activity you chose in the question above? Activity Difficulty (12)

Q38 How many times do you have to do the activity mentioned above on an average ride?
○ 1 (1)
O 2-3 (2)
O 4-5 (3)
○+ times (4) 
Q39 How long does that activity take you?

Under 5 minutes (1)

5-10 minutes (2)

O $10-15$ minutes (3)

O 15-20 minutes (4)

○ 20+ minutes (5) 